\title{
A new kentriodontid (Cetacea: Odontoceti) from the early to middle Miocene of the western North Pacific and a revision of kentriodontid phylogeny
}

\author{
Zixuan Guo ${ }^{\text {Corresp., } 1}$, Naoki Kohno ${ }^{1,2}$ \\ ${ }^{1}$ Faculty of Life and Environmental Sciences, University of Tsukuba, Tsukuba, Japan \\ 2 Department of Geology and Paleontology, National Museum of Nature and Science, Tsukuba, Japan \\ Corresponding Author: Zixuan Guo \\ Email address: guo_z@geol.tsukuba.ac.jp
}

A new species of an extinct dolphin belonging to the kentriodontids, i.e., Kentriodon sugawarai sp. nov., is described from the late early to earliest middle Miocene Kadonosawa Formation in Ninohe City, Iwate Prefecture, northern Japan. The holotype of Kentriodon sugawarai sp. nov., consists of a partial skull with ear bones, mandibular fragments, and some postcranial bones. This new species shares five unique characters with other species of Kentriodon. In addition, the new species differs from other species of the genus in displaying a narrow width of the squamosal lateral to the exoccipital in posterior view, the dorsolateral edge of the opening of the ventral infraorbital foramen that is formed by the maxilla and the lacrimal or the jugal, and at least three anterior dorsal infraorbital foramina. Our phylogenetic analysis based on 393 characters for 103 Odontoceti taxa yielded a consensus tree showing all previously identified kentriodontids as a monophyletic group that comprises the sister group of the crown Dephinoidea, which in turn include Delphinidae, Phocoenidae and Monodontidae. Our analysis also indicates that the distinct renewal of the acoustic apparatus (i.e., 13 out of 29 derived characters are from tympanoperiotic) would have occurred in the ancestral lineage of the Delphinoidea (sensu lato) including the monophyletic Kentriodontidae during their initial evolution and diversification. 
1

2 A new kentriodontid (Cetacea: Odontoceti) from the 3 early to middle Miocene of the western North Pacific

4 and a revision of kentriodontid phylogeny 5

6

7 Zixuan Guo ${ }^{1}$, Naoki Kohno ${ }^{1,2}$

8

$9{ }^{1}$ Faculty of Life and Environmental Sciences, University of Tsukuba, Tsukuba, Japan

102 Department of Geology and Paleontology, National Museum of Nature and Science, Tsukuba, 11 Japan

12

13 Corresponding Author:

14 Zixuan Guo ${ }^{1}$

15 University of Tsukuba, 1-1-1 Tennodai, Tsukuba, 305-8577, Japan

16 Email address: guo_z@geol.tsukuba.ac.jp

17 


\section{Abstract}

19 A new species of an extinct dolphin belonging to the kentriodontids, i.e., Kentriodon sugawarai

20

21

22

23

24

25

26

27

28

29

30

31

32

33

34

35

36

37

38

39

40

41

42

43

44

45

46

47

48

49

50

51

52

53

54

55

56

57

sp. nov., is described from the late early to earliest middle Miocene Kadonosawa Formation in Ninohe City, Iwate Prefecture, northern Japan. The holotype of Kentriodon sugawarai sp. nov., consists of a partial skull with ear bones, mandibular fragments, and some postcranial bones.

This new species shares five unique characters with other species of Kentriodon. In addition, the new species differs from other species of the genus in displaying a narrow width of the squamosal lateral to the exoccipital in posterior view, the dorsolateral edge of the opening of the ventral infraorbital foramen that is formed by the maxilla and the lacrimal or the jugal, and at least three anterior dorsal infraorbital foramina. Our phylogenetic analysis based on 393 characters for 103 Odontoceti taxa yielded a consensus tree showing all previously identified kentriodontids as a monophyletic group that comprises the sister group of the crown Dephinoidea, which in turn include Delphinidae, Phocoenidae and Monodontidae. Our analysis also indicates that the distinct renewal of the acoustic apparatus (i.e., 13 out of 29 derived characters are from tympanoperiotic) would have occurred in the ancestral lineage of the Delphinoidea (sensu lato) including the monophyletic Kentriodontidae during their initial evolution and diversification.

\section{Introduction}

Dephinoidea (i.e., Delphinidae, Monodontidae and Phocoenidae) has been thought to emerge in the early Miocene (Gatesy et al., 2013) and they are the most species-rich clade of living marine mammals in the world. However, their evolutionary origins are still puzzling. Proceeding in the dawn of Dephinoidea, small coastal odontocetes known as kentriodontids (Barnes \& Mitchell, 1984; Barnes, 1985; Muizon, 1988a) attained a high diversity during the period between the early and the late Miocene (Ichishima et al., 1995; Kazár \& Hampe, 2014; Peredo, Uhen, \& Nelson, 2018). This group had been considered to be placed among the stem delphinoids based on their primitive cranial morphologies and retention of several ancestral character states of odontocetes (Barnes, 1978). For instance, asymmetric nasals and premaxillae have commonly been observed in modern odontocetes. However, in part of the taxa referred to as members of kentriodontids, these bones are seemingly symmetrical. The interpretation of the evolutionary patterns of the Delphinoidea greatly relies upon the processes of morphological transformation in their stem group, while the phylogenetic relationships of such a stem group, presumably the kentriodontids, have remained debated.

In the initial stage of the studies on kentriodontids, they were considered as comprising a monophyletic family, i.e., Kentriodontidae (e.g., Barnes, 1978; Barnes, 1985; Muizon, 1988a, 1988b; Ichishima et al., 1995). However, recent studies have advocated that 'kentriodontids' are paraphyletic and should be subdivided into several clades by a different combination of taxa within Delphinida (including Lipotidae, Inioidea, and Delphinoidea) (e.g., Lambert et al., 2017; Peredo, Uhen \& Nelson, 2018; Kimura \& Hasegawa, 2019). Because several additional species of 'kentriodontids' have been recently reported, and molecular phylogenies of the cetaceans have

Peer) reviewing PDF | (2020:08:52427:2:0:CHECK 17 Jan 2021) 
58

59

60

61

62

63

64

65

66

67

68

69

70

71

72

73

74

75

76

77

78

79

80

81

82

83

84

85

86

87

88

89

90

91

92

93

94

95

96

97

been established in the last decade (e.g., McGowen, Spaulding \& Gatesy, 2009; McGowen et al., 2011; McGowen et al., 2020; Geisler et al., 2011), a more comprehensive reappraisal of the phylogeny of this group is necessary. In particular, Peredo, Uhen \& Nelson (2018) redefined the family Kentriodontidae, only including Wimahl, Kampholophos and Kentriodon. However, some other phylogenetic studies (e.g., Murakami et al., 2014; Tanaka \& Fordyce, 2014, 2016; Tanaka et al., 2017; Lambert et al., 2018a, 2018b), using different character sets and data matrices displayed some kentriodontid taxa in a different phylogenetic topology. In other words, the relationships of taxa originally referred to the family 'Kentriodontidae' are still debated (Fig. 1).

Here, we describe a new species of kentriodontid from the early to middle Miocene of Japan (Fig. 2). The holotype specimen includes a partial skull with well-preserved tympanoperiotics. We also reassess the phylogenetic relationships of kentriodontids and discuss on the evolution of Delphinoidea, including kentriodontids.

\section{Materials \& Methods}

\section{Nomenclatural acts}

The electronic version of this article in Portable Document Format (PDF) will represent a published work according to the International Commission on Zoological Nomenclature (ICZN), and hence the new names contained in the electronic version are effectively published under that Code from the electronic edition alone. This published work and the nomenclatural acts it contains have been registered in ZooBank, the online registration system for the ICZN. The ZooBank LSIDs (Life Science Identifiers) can be resolved and the associated information viewed through any standard web browser by appending the LSID to the prefix http://zoobank.org/. The LSID for this publication is: urn:lsid:zoobank.org:pub:B0E9467F-CDD3-4AF4-83FE40CE09D15700. The online version of this work is archived and available from the following digital repositories: PeerJ, PubMed Central and CLOCKSS

\section{Anatomical terminology}

We follow Mead \& Fordyce (2009) and Ichishima (2016) for the terminology of the skull.

\section{Phylogenetic Methods}

The phylogenetic position of the new specimen described here was analyzed based on a character list and the character matrix that stems from the works by Tanaka et al. (2017) and Lambert et al. (2017). The character list and data matrix by Tanaka et al. (2017) derive from those by Geisler et al. (2011) via the addition of characters by Murakami et al. (2012) to understand interspecific relationships of the Phocoenidae within the crown Delphinoidea, and the subsequent modifications by Tanaka \& Fordyce (2014). The data matrix by Tanaka et al. (2017) included 87 taxa and 284 characters, but this matrix only included 3 kentriodontid taxa: i.e., Atocetus iquensis Muizon 1988b, Hadrodelphis calvertense Dawson 1996a, and Kentriodon pernix Kellogg 1927. By contrast, the data matrix by Lambert et al. (2017) was also based on Geisler et al. (2011) and Geisler, Godfrey \& Lambert (2012), but it included 112 taxa and 324 characters, with 12 
98

99

100

101

102

103

104

105

106

107

108

109

110

111

112

113

114

115

116

117

118

119

120

121

122

123

124

125

126

127

128

129

130

131

132

133

134

135

136

137

kentriodontid taxa: i.e., Atocetus iquensis, Atocetus nasalis Muizon 1988b, Delphinodon dividum True 1912, Hadrodelphis calvertense, Kampholophos serrulus Rensberger 1969, Kentriodon pernix, Lophocetus calvertensis Cope 1867, Lophocetus repenningi Barnes 1978, Macrokentriodon morani Dawson 1996b, Pithanodelphis cornutus Abel 1905, Rudicetus squalodontoides Bianucci 2001, and Tagicetus joneti Lambert, Estevens \& Smith 2005. However, the character set used by Lambert et al. (2017) for their phylogenetic analysis was originally elaborated for taxa within earlier branching clades of the Odontoceti (e.g., Geisler et al., 2011; Lambert et al., 2017; Peredo, Uhen \& Nelson, 2018; Kimura \& Hasegawa, 2019). Consequently, the focus of these two streams of studies on the odontocete phylogeny (e.g.,Tanaka et al., 2017 and e.g., Lambert et al., 2017) have not fully overlapped with each other, in other words, the included taxa of kentriodontids and character combination to analyze their phylogenetic relationships were far too different to each other. To solve these issues, we elaborated a phylogenetic dataset based on the combined characters and kentriodontid taxa from previous studies such as Geisler, Godfrey \& Lambert (2012), Murakami et al. (2012), Tanaka \& Fordyce (2014), Tanaka et al. (2017), Lambert et al. (2017), Peredo, Uhen \& Nelson (2018), and Kimura \& Hasegawa (2019). The resulting data matrix that is used herein is based on 103 taxa, including almost all kentriodontids, and 393 morphological characters (see Supplemental Information), with a tree constraint based on the molecular phylogenetic studies of the extant cetaceans by McGowen, Spaulding \& Gatesy (2009), McGowen et al. (2011) and McGowen et al. (2020). Regarding the kentriodontids, we included the following 15 taxa into our data matrix (see also Supplemental Information): Atocetus nasalis from the late Miocene of California, USA (Muizon, 1988b), Delphinodon dividum from the early Miocene of Meryland, USA (True, 1912), Kampholophos serrulus from the early Miocene of California, USA (Rensberger, 1969), Kentriodon diusinus Salinas-Márquez et al. 2014 from the middle Miocene of Baja California, Mexico (Salinas-Márquez et al., 2014), Kentriodon nakajimai Kimura \& Hasegawa 2019 from the middle to late Miocene of Japan (Kimura \& Hasegawa, 2019), Kentriodon obscurus Kellogg 1931 from the middle Miocene of California, USA (Kellogg, 1931; Barnes \& Mitchell, 1984), Kentriodon schneideri Whitmore \& Kaltenbach 2008 from the middle Miocene of North Carolina, USA (Whitmore \& Kaltenbach, 2008), Liolithax pappus from the middle Miocene of Maryland, USA (Barnes, 1978), Lophocetus calvertensis from the late Miocene of Maryland, USA (Cope, 1867), Lophocetus repenningi from the middle Miocene of California, USA (Barnes, 1978), Macrokentriodon morani from the middle Miocene of Maryland, USA (Dawson, 1996b), Pithanodelphis cornutus from the late Miocene of Belgium (Abel O. 1905), Rudicetus squalodontoides from the early to late Miocene of Italy (Bianucci, 2001), Tagicetus joneti from the middle Miocene of Portugal (Lambert, Estevens \& Smith, 2005), and Wimahl chinookensis Peredo, Uhen \& Nelson 2018 from the early Miocene of Washington, USA (Peredo, Uhen \& Nelson, 2018).

The phylogenetic analysis was performed with TNT 1.5 (Goloboff, Farris \& Nixon, 2008; Goloboff \& Catalano, 2016). All characters were treated as unweighted and unordered, using the "New Technology Search" task to find minimum length trees 1,000 times, under a tree 
138 constraint based on molecular evidence from the extant taxa (McGowen, Spaulding \& Gatesy,

139

140

141

142

143

144

145

146

147

148

149

150

151

152

153

154

155

156

157

158

159

160

161

162

163

164

165

166

167

168

169

170

171

172

173

174

175

176

177

2009; McGowen et al., 2011; McGowen et al., 2020).

\title{
SYSTEMATIC PALEONTOLOGY
}

\author{
CETACEA Brisson, 1762
}

ODONTOCETI Flower, 1867

DELPHINIDA Muizon, 1988a

KENTRIODONTIDAE Slijper, 1936

Emended Diagnosis of Kentriodontidae: Differing from other delphinidan families and superfamilies (i.e., Delphinidae, Phocoenidae, Monodontidae, Lipotidae, and Inioidea) in displaying the following suite of derived character states: premaxillae are compressed mediolaterally at anterior part of the rostrum (Chr. 3), the mesorostral groove is constricted posteriorly, anterior to the nares and behind the level of the antorbital notch, then rapidly diverging anteriorly (Chr. 7), anterior edge of the supraorbital process is oriented anterolaterally, forming an angle between $35^{\circ}$ and $60^{\circ}$ (Chr. 50), the dorsolateral edge of internal opening of the infraorbital foramen is formed by the lacrimal or the jugal (Chr. 58), the infratemporal crest forms a well-defined curved ridge on the posterior edge of the sulcus for the optic nerve (Chr. 64), the premaxillary foramen is located medially (Chr. 72), the alisphenoid is broadly exposed laterally in the temporal fossa (Chr. 160), suture between both the palatines and both the maxillae is straight transversely or bowed anteriorly (Chr. 179), the external auditory meatus is wide (Chr. 225), the basioccipital crests form an angle of approximately $15-40^{\circ}$ in ventral view (Chr. 229), the hypoglossal foramen is separated from the jugular foramen or the jugular notch by thick bone (Chr. 231), most convex part of the pars cochlearis is on the ventrolateral surface (Chr. 283).

Kentriodon Kellogg, 1927

Emended Diagnosis of Genus: Kentriodon differs from other genera of kentriodontids by the following unique characters combination: the cheek tooth entocingulum is present (Chr. 28); the dorsal edge of the orbit is low, either in line with the edge of the rostrum or slightly above it (Chr. 47); the position of the inflection of premaxilla is located in line with the posterior half of the supraorbital process or in line with the postorbital process of frontal (Chr. 109); in lateral view, the dorsal edge of the zygomatic process preserves a distinct dorsal flange or process near the anterior end, articulates with the frontal (Chr. 164); and the postzygapophysis is appearing as a crest, elongated dorsolaterally from anterior view (Chr. 328). In this regard, Rudicetus squalodontoides could also be included in this genus.

Kentriodon sugawarai sp. nov.

Peer) reviewing PDF | (2020:08:52427:2:0:CHECK 17 Jan 2021) 
178

179

180

181

182

183

184

185

186

187

188

189

190

191

192

193

194

195

196

197

198

199

200

201

202

203

204

205

206

207

208

209

210

211

212

213

214

215

216

217

(Figs. 3-12, Table 1)

LSID: urn:Isid:zoobank.org:act:0D209916-B472-44A7-B7AB-29682FA945C4

Holotype: NMHF 999, incomplete skull including most of the neurocranium and a proximal portion of the rostrum, one tooth, the right tympanoperiotics and malleus, fragments of the left and right mandibles, and the partial atlas.

Diagnosis of Species: Kentriodon sugawarai sp. nov. differs from K. schneideri by the convex occipital shield (Chr. 176). It differs from K. pernix, K. nakajimai and K. obscurus by the following characters: the dorsolateral edge of the opening of the ventral infraorbital foramen is formed by the maxilla and the lacrimal or the jugal (Chr. 58), at least three anterior dorsal infraorbital foramina (Chr. 65), anterolateral corner of the nasal lacking a distinct inflated process (Chr. 136), narrow width of the squamosal lateral to the exoccipital (Chr. 170), anterior level of the pterygoid sinus fossa is interrupted posterior to (or at the level of) the antorbital notch (Chr. 193), and the ventral edge of the anterior process of the periotic is clearly concave in lateral view (Chr. 245). Further differs from Kentriodon hoepfneri and K. nakajimai by the apex of the postorbital process of the frontal that is directed ventrally rather than posterolaterally, by the angle between anterior process of periotic and anterior edge of pars cochlearis that is nearly 90 degrees. It differs from $K$. nakajimai, $K$. diusinus and $K$. schneideri by displaying a deep emargination of the posterior edge of the zygomatic process by the neck muscle fossa. It differs from Kentriodon hobetsu, K. schneideri and K. pernix by the transversely narrower exoccipital and by the maxillae that makes a deep fossae on each side at the vertex. It differs from $K$. obscurus and K. pernix by the aperture for the cochlear aqueduct that is transversely smaller than the aperture for the vestibular aqueduct. It further differs from $K$. pernix by having a shallower lateral furrow of the tympanic bulla.

Etymology: The species is named in honor of Mr. Kohei Sugawara, the former director of the Ninohe Museum of History and Folklore, for his longstanding contributions to geology and paleontology as well as local history of the Ninohe district, and as a sign of gratitude for his encouragement and assistance to both of us throughout this study.

Type Locality: The holotype was collected in the 1940s from a locality close to the Mabechi River, Ninohe City, Iwate Prefecture, Japan. Approximate geographical coordinates: $40^{\circ} 31^{\prime} \mathrm{N}$, $141^{\circ} 31^{\prime} \mathrm{E}$; (Fig. 2).

Formation and Age: Although the precise locality of NMHF 999 is at present uncertain, and the exact horizon from which NMHF 999 was collected is also unclear, the siltstone matrix adhering to NMHF 999 has produced a diatom flora that includes Denticulopsis praelauta (Oishi et al., 1999). Consequently, NMHF 999 should come from the middle or upper portions of the Kadonosawa Formation, because the Shikonai Siltstone Member of this formation is dominated by silts and very fine sandstones. The Shikonai Siltstone Member of the Kadonosawa Formation is widely distributed in Ninohe City, including the provenance area of NMHF 999. The siltstone layers of the Shirikonai Siltstone Member of the Kadonosawa Formation have produced a rich diatom assemblage, that has been referred to the Denticulopsis praelauta Zone (NPD 3B) 
218 (TuZino \& Yanagisawa, 2017; Tuzino et al., 2018). The range in age of this zone spans

219 chronostratigraphically between 16.3 and $15.9 \mathrm{Ma}$ (Yanagisawa \& Akiba, 1998), latest

220 Burdigalian to earliest Langhian, latest early to earliest middle Miocene. The main part of the

221 Kadonosawa Formation has yielded abundant molluskan fossils (Chinzei, 1966), as well as a

222 tooth of Desmostylus (Oishi \& Kawakami, 1984). Based on ostracods (Irizuki \& Matsubara,

223 1994) and benthic foraminifera (Kamemaru, Matsubara \& Irizuki, 1995), the depositional

224 environment of the Shikonai Siltstone Member of the Kadonosawa Formation conforms to

225 sublittoral to bathyal settings.

226

\section{DESCRIPTION}

\section{Cranium}

229 The cranium lacks most of the rostrum (Fig. 3), and the left orbit and parts of the left and right squamosals are also missing. In ventral view, the cranium has been dorsoventrally crushed in the area of the choanae. The choanae are cracked and not connected with the bony nares, anteriorly depressed by secondary deformation (Fig. 4). In dorsal view, the nasals and the premaxillae are almost symmetrical, while the midline of the occipital condyles is slightly skewed to the right. The cranium underwent some degree of oblique deformation, from the upper right to the lower left and the dorsal part of the cranium might fall left by this deformation. In lateral view, the temporal fossa is anteroposteriorly long and dorsoventrally high. The vertex is low and flat, being formed by the frontals and the nasals.

238

\section{Premaxilla}

240

The premaxillae are symmetrical. Most of the rostral portion of premaxillae is broken away. The broken section is just anterior to the antorbital notch. The premaxillary foramen is just posterior to the broken section, and at the same level as the antorbital notch. Anteromedial to the premaxillary foramen, the anteromedial sulcus and the prenarial triangle are not preserved. No posteromedial sulcus of the premaxilla was observed. The lateral margin of each side of the premaxilla is also broken, and only a recognizable premaxillary surface on right side of the maxilla remains. Anterior to the bony nares, the premaxillae are dorsoventrally thin and flat. The posterolateral sulcus cannot be recognized, and the premaxillary sac fossa is weekly depressed. In lateral view, the ascending process of the premaxilla forms an angle of about $20^{\circ}$ from the anteroposterior axis of the cranium (Fig. 5). The knob-like posterior end of the premaxilla contacts the anterolateral corner of the nasal at a level slightly lower than the vertex of the cranium.

252

253

\section{Maxilla}

254

255

The left maxilla is broken laterally, but the right antorbital notch is preserved. The maxillary-

256 palatine suture and the cross-section of the infraorbital canal are observed along the broken section (Fig. 6). The maxilla is generally flat transversely in the antorbital region, and there is no indication that any maxillary crest was present. The lateral margin of the maxilla is flat in its 
258

259

260

261

262

263

264

265

266

267

268

269

270

271

272

273

274

275

276

277

278

279

280

281

282

283

284

285

286

287

288

289

290

291

292

293

294

295

296

297

orbital area, whereas it is slightly concave dorsally and posteriorly to the orbit. There are three anterior and one posterior dorsal infraorbital foramina on the right maxilla (Fig. 3). The anteriormost of these foramina is located just beside the maxilla-premaxilla suture, anteromedial to the antorbital notch; other small anterior dorsal infraorbital foramina are located at the level of the orbit. The posterior dorsal infraorbital foramen is the largest, and its opening is located on the ascending process at the anteroposterior level of the corresponding nasal. The maxilla rises towards the vertex, gently at the ascending process but steeply along the lateral face of the vertex. Although the vertex is low, the maxilla faces laterally just lateral to the nasal and makes a deep fossa on each side, defined medially by the nasal and posteriorly by the nuchal crest. In dorsal view, the posterior and lateral margins of the right maxilla are semicircular, and the posteromedial margin contacts the supraoccipital. In lateral view, the maxilla forms a thin plate and covers the frontal dorsally in orbital area. It gradually thickens anteriorly at the antorbital process. In ventral view, the right ventral infraorbital foramen is preserved, while the lateral edge of the left ventral infraorbital foramen is broken away. The dorsolateral edge of the opening of the ventral infraorbital foramen is formed by the maxilla and the lacrimal or the jugal.

\section{Palatine and Pterygoid}

The posterior halves of both the palatines are preserved. The palatine-maxilla suture is visible from the anterior side through the broken transverse section of the rostrum base (Fig. 6). The palatine contacts the maxilla dorsally and is dorsoventrally thinner than the maxilla. The left and right palatines are not separated medially at the level of the transverse section, just anterior to the antorbital notch. The left side of the palatine is broken laterally, but the parasagittal section of the left infraorbital canal is observed (Fig. 4). The palatine-maxilla suture is not clear in the parasagittal section, and the ventromedial edge of the ventral infraorbital foramen is uncertain.

The pterygoids are well preserved, including both the lateral and ventral laminae of the pterygoid and the pterygoid hamuli. The anterior tip of the pterygoid is located slightly posteriorly to the level of the antorbital notch. The pterygoid sinus is ventrally covered by the pterygoid. The anterior edge of the pterygoid sinus is at the level of the antorbital notch. The palatal surface of the pterygoid is flat and ventrally convex. The sagittal portion of the two pterygoids do not contact each other medially in their posterior portion. The pterygoid hamulus is short and preserving the hamular crest. The hamular crests of the right and left pterygoids diverge posteriorly in ventral view, and extend to the posterolateral most of the lateral and ventral laminae of the pterygoid, just posterior to the infratemporal crest of the frontal. The medial lamina forms the anterolateral wall of the internal nares. Although the pterygoidbasioccipital suture is not preserved clearly, the posterior lamina overlaps the basioccipital crest. It forms the pharyngeal crest and covers the alisphenoid ventrally.

\section{Vomer}

The vomer is visible dorsally. When viewed from the anterior transverse section (Fig. 6), the premaxilla does not roof the vomer dorsally. The mesorostal groove is widely open as a U- 
298 shaped groove, starting $11 \mathrm{~mm}$ anterior to the anterior edge of the bony nares. In ventral view, 299 the vomer does not seem to make contact with its posterior part due to deformation. It twists left 300 and ventral to the posterior part (Fig. 6). The posterior part of the vomer is posteriorly overhung 301 beneath the basisphenoid.

302

303

304

305

\section{Presphenoid}

The nasal septum is narrow transversely and straight dorsally. It is as high as the level of the nasal process of the premaxilla and posteriorly contacts both the nasals. Because of this, the cribriform plate cannot be distinguished in dorsal view.

307

308

309

\section{Nasal}

310

The shape of the nasal in dorsal view is subtriangular, and its transverse width is greater than its anteroposterior length. The left and right nasals are symmetrical. The nasals are slightly wider than the widest part of the bony nares. It preserved a posteriorly directed tip, slightly wider than its anterior margin. The lateral margin contacts the posterior end of the premaxilla anterolaterally and contacts the maxilla laterally. The nasals also contact the frontals posteromedially. The dorsal surface of the nasal is flat except for the slightly concave anterolateral part. There is no indication of an internasal fossa and the internasal suture is a shallow trough. In dorsal view, the anterior border of the nasal is slightly retracted posteriorly from the bony nares.

319

320 The frontal is only exposed dorsally at the vertex. In dorsal view, the frontal is separated from the maxilla by the nasal. The dorsal exposure of the joined frontals on the vertex is elliptical, and each frontal contacts the corresponding nasal anterolaterally and the supraoccipital posteriorly, but not contacting with the maxilla laterally. The frontal at the vertex is slightly higher than the nasal, being the highest point of the cranium. In lateral view, the orbit is markedly concave and low, in line with the lateral edge of the posterior part of the rostrum (Fig. 5). In lateral view, the preorbital process is thick anteriorly. While the anteriormost part of the frontal is broken, the frontal-lacrimal suture is not clear. Although being distally broken, the postorbital process is somewhat transversely narrow and triangular at the base, being directed posteroventrally or ventrally. Both the fossae for the preorbital and the postorbital lobes of the pterygoid sinus are shallow or absent. The frontal groove is deep medially, extends anterolaterally beyond the level of the ventral infraorbital foramen. The infratemporal crest is curved, distinct just lateral to the optic canal.

\section{Lacrimojugal Complex}

334 The left antorbital process is broken, and the right antorbital process is also broken anteriorly and laterally, so that the shape and the anteriormost portion of the antorbital process is not clear. Although both the lacrimal-maxilla suture and the lacrimal-jugal suture are not clear in dorsal view, the lacrimal-maxilla suture might be observable in anterior view along the broken section 
338

339

340

341

342

343

344

345

346

347

348

349

350

351

352

353

354

355

356

357

358

359

360

361

362

363

364

365

366

367

368

369

370

371

372

373

374

375

376

377

of the antorbital process. Here the lacrimal appears as thicker than the maxilla. The right jugal contacts the lacrimal exactly at the posterior end of the antorbital notch. The main part of the right jugal is broken, only preserved as a short narrow base of the maxillary process.

\section{Squamosal}

The right squamosal is almost missing, while the left squamosal is only preserved the postglenoid process, with the zygomatic process being lost. The zygomatic process of the squamosal likely to be long because the postorbital process is relatively far from the postglenoid process. The squamosal fossa is incomplete anteriorly, but it is shallow and somehow longer anteroposteriorly and transversely wide, and it faces dorsally. The lateral margin of the fossa is visible in dorsal view. The mandibular fossa is not preserved, while the tympanosquamosal recess can be observed medially. The tympanosquamosal recess is flat and wide, and its ventral surface is wrinkled. The falciform process is not well preserved. The dorsal roof of the external auditory meatus is preserved and is distinctively narrow, but the postglenoid process just in front of the external auditory meatus is not clear because of insufficient preservation.

\section{Supraoccipital}

The supraoccipital extends broadly in dorsal view. The nuchal crest is trapezoidal in outline, while it is medially concave at the level of the temporal fossa. It expands ventrolaterally toward the exoccipital. In posterior view, the supraoccipital is inclined anteriorly with a reduced dorsoventral height. The occipital shield is concave anterodorsally and convex posteroventrally. Anteromedially, just posterior to the nuchal crest, the supraoccipital is concave dorsally, forming a fossa whose anteriormost surface faces posteriorly. Posteriorly, the occipital shield bulges medially (Fig. 7) and it is collapsed along the right margin, most likely as a result of deformation. The supraoccipital is fused with the exoccipital along an undefined suture. There is no indication of an external occipital crest.

\section{Exoccipital}

The exoccipital is wide in posterior view. It extends laterally from the temporal crest and is fused with the basioccipital ventrally. The temporal crest overhangs the exoccipital posterolaterally, and extends nearly to the posterior most level of the cranium, not taking account of the occipital condyles. The occipital condyle is prominent, and the condylar neck is well developed, while there is no indication of a dorsal condyloid fossa. The foramen magnum is almost circular, being only slightly higher than wide. In posterior view, the jugular notch is deep and narrow. The paroccipital process is wide. The hypoglossal foramen opens in the jugular notch. The paroccipital concavity is deep.

\section{Basioccipital}

The basioccipital basin is broad and strongly concave in posterior view. The basioccipital crests face ventromedially. In ventral view, the basioccipital crest width is transversely narrow. 
378 Anteriorly, the basioccipital contacts with the posterior lamina of the pterygoid. Its posterior 379 margin is rounded. Medial to the crest, the ventral surface of the basioccipital is flat. The 380 muscular tubercle is not developed in the basioccipital basin.

381

382

383

384

385

386

387

388

389

390

391

392

393

394

395

396

397

398

399

400

401

402

403

404

405

406

407

408

409

410

411

412

413

414

415

416

417

\section{Periotic}

The right periotic is preserved (Figs. 8 and 9). In dorsal and ventral views, the apex of the anterior process is mediolaterally flattened. Both anteroventral and anterodorsal angles are respectively tapered and directed anteriorly, reaching the same level anteriorly and separated by the anterior keel. The anteroposterior length of the anterior process is nearly the same as that of the pars cochlearis. The anterior incisure is deep, and it separates the anterior process from the pars cochlearis. In lateral view, the ventral surface of the parabullary ridge is concave. There is a flat surface anterior to the fovea epitubaria, which is circular and about $2 \mathrm{~mm}$ long, which might correspond to a very shallow anterior bullar facet. The fovea epitubaria is broad, and it receives with no fusion the accessory ossicle of the tympanic bulla. There is a fossa posteromedial to the fovea epitubaria and anteromedial to the mallear fossa. It receives the tubercle of the malleus. The mallear fossa is rounded and faces ventrally rather than medially. The lateral tuberosity is bulbous lateral to the mallear fossa. The epitympanic hiatus is concave just posterior to the lateral tuberosity. The hiatus just located posteromedially to the facial canal. The vestibular window is rounded and slightly larger than the opening for the facial canal.

The medial outline of the pars cochlearis is rounded and compressed dorsoventrally. The cochlear window opens on the posterior wall of the pars cochlearis. The aperture for the cochlear aqueduct opens dorsally and is located close to the vestibular aqueduct at the same transverse level as the medial edge of the internal acoustic meatus. The aperture for the vestibular aqueduct is two times larger than the aperture for the cochlear aqueduct and located slightly posteriorly to the aperture for the cochlear aqueduct. The internal acoustic meatus is large and funnel-shaped, with an anterolateral-posteromedial axis. The anteriormost tip of the internal acoustic meatus extends in the anterior incisure. The foramen singulare is located closer to the proximal opening of the facial canal than to the spiral cribriform tract, and it is separated by partitions from the proximal opening of the facial canal and the spiral cribriform tract. The proximal opening of the facial canal is located slightly anterior to the spiral cribriform tract. The area cribrosa media has almost the same size as the spiral cribriform tract. The posterior process extends for a short distance anteroventrally, while its posterior edge is directed ventrally. In lateral view, the posterior and dorsal faces of the posterior process draw a blunt right angle. The posterior bullar facet is smooth and faces anteroventrally.

\section{Tympanic bulla}

The right tympanic bulla only lacks the anterodorsal crest (Figs. 10 and 11). The accessory ossicle is preserved but detached from the tympanic bulla. The tympanic bulla is narrow and long in lateral view, and its ventral margin is slightly concave in lateral view. The lateral furrow is absent or very shallow. The disarticulated accessory ossicle is rounded, $8.3 \mathrm{~mm}$ in width. It 
418 originally occupied the fovea epitubaria of the periotic. In ventral view, there is an

419 anteroposterior linear fracture surface on the accessory ossicle, for the attachment to the outer lip

420 of the tympanic. The involucrum tapers anteriorly, and the anterior spine is absent. The dorsal

421 and ventral margins of the involucrum are parallel and the dorsal margin is excavated just

422 anterior to the posterior process. The ventromedial keel on the involucrum is not clearly defined.

423 The interprominential notch is shallow and is followed anteriorly by the median furrow. The

424 median furrow is shallow. It widens anteriorly and points laterally. In dorsal view, the sigmoid

425 process is large and rounded, and it partly covers the conical process. The posterior edge of the

426 sigmoid process is thick. The conical process is dorsally high. The inner and outer posterior

427 prominences extend posteriorly to the same level, and they are almost equal in transverse width.

428 The posterior process, which is broken at its base, is rounded in outline and thick. The facet for

429 the posterior process of the periotic is smooth. The elliptical foramen can be observed between

430 the outer and inner posterior pedicles.

431

432

433

434

435

436

437

438

439

440

441

442

443

444

445

446

447

448

449

450

451

452

453

\section{Malleus}

The malleus is isolated from the periotic (Fig. $12 \mathrm{~A}-\mathrm{F}$ ). The head is high anteromedially. The ventral margin of the tubercule is concave. The manubrium of the malleus forms a hook-like process at the medial margin, which directs anteriorly. The insertion for the tendon of the $\mathrm{m}$. tensor tympani opens ventrally. The processus muscularis is small.

\section{Mandible}

Both the left and right mandibles are partly preserved (Fig. $12 \mathrm{~K}-\mathrm{N}$ ), but the right mandible only preserves its posterior part, while the left mandible preserves its posteroventral part including the angular process and the ventral half of the mandibular condyle. The mandibular foramen is shallow mediolaterally. The left mandible does not preserve the anterior margin of the mandibular foramen. The posterior margin of the angular process is rounded, and the medial surface is concave. The mandibular condyle is located more posteriorly than the angular process and is separated from the latter by an anteriorly inward, deep, rounded curve. The medial surface of the condyle is concave and the condylar articular surface is not preserved.

\section{Tooth}

One isolated tooth is preserved (Fig. $12 \mathrm{G}-\mathrm{J}$ ). It is small and conical, at least $27 \mathrm{~mm}$ long and with a maximum diameter of the root of $6.3 \mathrm{~mm}$. The crown surface is smooth and its apex is curved. The tooth root is also smooth and conical, and it is 1.5 times longer than the crown. The cementum of the root is just slightly thicker than the crown, and the tip of the root is recurved in a direction that is at right angle with the curve of the crown's apex.

454

455

\section{Vertebra}

456 Only a fragment of the atlas is preserved (Fig. $12 \mathrm{O}, \mathrm{P}$ ). The ventral part of the bone, without the 457 upper transverse processes, is preserved. In posterior view, the posterior articular surface is not 
458

459

460

461

462

463

464

465

466

467

468

469

470

471

472

473

474

475

476

477

478

479

480

481

482

483

484

485

486

487

488

489

490

491

492

493

494

495

496

497

well preserved, but it was originally not fused with the axis. In dorsal view, the anterior tubercle is short anteroposteriorly and relatively high dorsoventrally. It bears a V-shaped crest on its anterior surface, starting from the ventral most of the anterior articular facet and running to the ventral apex of the anterior tubercle.

\section{Results of Phylogenetic Analyses}

Our phylogenetic analysis found 256 most parsimonious trees with 3424 steps of total branch length. Each tree has a consistency index of 0.197 and a retention index of 0.564 . The $50 \%$ majority rule consensus of those trees is shown in Figure 13, and the strict consensus tree is shown in the Figure 14 (see also Supplemental Information). Both consensus trees show that all the species that were previously identified as kentriodontids form a monophyletic group that is positioned as the sister group to the crown Delphinoidea (i.e., Delphinidae, Phocoenidae and Monodontidae), and the clade Lipotidae + Inioidea is basal to the clade Delphinoidea (monophyletic Kentriodontidae + crown Delphinoidea).

Delphinoidea differ from Lipotidae + Inioidea by the following 11 synapomorphies: the anterior sinus fossa is located between the anterior extremity of the pterygoid sinus and the posterior extremity of the upper tooth row (Chr. 19), the apex of the postorbital process of frontal is directed ventrally (Chr. 61), the width of the premaxillae at the antorbital notches is moderate (Chr. 67), the apex of the anterior process of the periotic is thickened by the prominent dorsal tubercle that gives to this apex a rectangular section on the plane of the body of the periotic (Chr. 239), the contact of the anterior process of the petrosal with a portion of the ectotympanic bulla anterior to the accessory ossicle is absent (Chr. 249), the periotic articulates with the squamosal along the hiatus epitympanicus and adjacent regions on the posterior process (Chr. 286), the posterior process of the periotic is long (Chr. 292), lateral furrow of the tympanic bulla is present as a shallow groove (Chr. 303), the ventral margin of the tympanic bulla is concave in lateral view (Chr. 307), the basihyal and the thyrohyal are fused (Chr. 322), and the roof of the neural canal of the atlas is straight (Chr. 327).

The monophyly of Kentriodontidae is supported by the following 14 synapomorphies: premaxillae are compressed mediolaterally at anterior of the rostrum (Chr. 3), the mesorostral groove is constricted posteriorly, anterior to the nares and behind the level of the antorbital notch, then rapidly diverging anteriorly (Chr. 7), anterior edge of the supraorbital process is oriented anterolaterally, forming an angle with the longitudinal axis of the skull between $35^{\circ}$ and $60^{\circ}$ (Chr. 50), the dorsolateral edge of internal opening of the infraorbital foramen is formed by the lacrimal or the jugal (Chr. 58), the infratemporal crest forms well-defined curved ridge on the posterior edge of sulcus for the optic nerve (Chr. 64), the premaxillary foramen is located medially (Chr. 72), the alisphenoid is broadly exposed laterally in the temporal fossa (Chr. 160), suture between the joined palatines and the joined maxillae is straight transversely or bowed anteriorly (Chr. 179), the external auditory meatus is wide (Chr. 225), angle formed by basioccipital crests as approximately $15-40^{\circ}$ in ventral view (Chr. 229), the hypoglossal foramen is separated from the jugular foramen or the jugular notch by thick bone (Chr. 231), most convex 
498

499

500

501

502

503

504

505

506

507

508

509

510

511

512

513

514

515

516

517

518

519

520

521

522

523

524

525

526

527

528

529

530

531

532

533

534

535

536

537

part of the pars cochlearis is on the ventrolateral surface (Chr. 283), the basihyal is fused with the thyrohyal (Chr. 332), and the lateral edge of transverse processes of lumbar vertebrae makes an angle of $45^{\circ}$ or more relative to the parasagittal plane (Chr. 334). However, the last two characters (i.e., Chrs. 332 and 334) are not known for most kentriodontid taxa.

The monophyly of the genus Kentriodon was recognized by five unique characters as was mentioned in the generic diagnosis. In particular, 'Rudicetus' squalodontoides was recognized as a sister taxon to Kentriodon diusinus and consequently bracketed among the species of Kentriodon. NMHF 999 was also nested in the genus Kentriodon and recognized as a sister taxon to the clade of K. pernix, K. nakajimai and K. obscurus (Fig. 13).

\section{Comparison}

As in most kentriodontids, the premaxillae and nasals of NMHF 999 are symmetrical. Also, the vertex of NMHF 999 is low and flat, similar to most species of Kentriodon. Unlike the condition in K. hobetsu, K. pernix and K. schneideri, the maxillae of NMHF 999 makes a deep fossae on each side and faces laterally at the vertex, intently medially by the nasal and posteriorly by the nuchal crest. This feature is similar to K. nakajimai and some other genera of kentriodontids such as Delphinodon dividum, Hadrodelphis calvertense, Liolithax pappus, Lophocetus calvertensis, Lophocetus repenningi and Macrokentriodon morani. The nasal septum of NMHF 999 is high, as high as the nasal process of the premaxilla. This feature is unique to NMHF 999 and unlike other Kentriodon nor other genera of kentriodontids. Due to the nasal septum is fragile, it is not always optimally preserved in fossils. In dorsal view, the nasal of NMHF 999 is similar to that in K. pernix, D. dividum and Tagicetus joneti. The condition is different from that in K. pernix and D. dividum, as the nasal of NMHF 999 posteriorly extends to the nuchal crest, and the frontal is not contacting with the maxilla laterally. However, in $T$. joneti, it also has a well-developed posterolateral projection of the nasal. The supraoccipital of NMHF 999 is concave dorsally and anteriorly, just posterior to the line of the nuchal crest at the vertex. It is similar to the condition in K. nakajimai, K. schneideri, and 'R.' squalodontoides, but different from some other Kentriodon species, such as K. pernix and K. hobetsu. In dorsal view, the occipital shield of NMHF 999 is convex posteriorly as in K. pernix. Although this feature may be emphasized by deformation in NMHF 999, the same portion is straight posteriorly in most other species of Kentriodon. In ventral view, the tympanosquamosal recess of NMHF 999 is flat and wide, similar to that in K. pernix and K. hobetsu.

The apex of the anterior process of the periotic of NMHF 999 is directed anteriorly in dorsal views, and the anteroposterior length of the anterior process is as great as the length of the pars cochlearis. These conditions are similar to those in H. calvertense, W. chinookensis,

Liolithax kernensis and L. pappus. In contrast, in K. nakajimai, K. obscurus, K. hoepfneri and $K$. pernix, the apex of the anterior process of the periotic is directed somewhat anteromedially, and the anterior process of the periotic is shorter than the pars cochlearis. In NMHF 999, the lateral tuberosity of the periotic is ventrally as high as that in K. nakajimai and K. pernix, but it is higher in $K$. hoepfneri and other genera of kentriodontids (i.e., L. pappus, W. chinookensis, K. serrulus 
538

539

540

541

542

543

544

545

546

547

\section{8}

549

550

551

552

553

554

555

556

557

558

559

560

561

562

563

564

565

566

567

568

569

570

571

572

573

574

575

576

577

and Sophianacetus commenticius). In dorsal view, the anterolateral margin of the pars cochlearis is separated from the anterior process by an anterior fissure of the facial canal in NMHF 999.

This feature is also observed in K. pernix, L. kernensis and W. chinookensis. The interprominential notch of the tympanic bulla is shallow in NMHF 999, as in D. dividum K. serrulus and $W$. chinookensis, while this notch is much deeper in A. iquensis, K. nakajima, $K$. pernix, and S. commenticius.

Based on our phylogenetic analysis and those comparisons, identification of NMMF 999 as a distinct species within the genus Kentriodon is warranted. Thus, we propose the new species Kentriodon sugawarai sp. nov.

\section{Discussion and Conclusions}

\section{Phylogenetic Position of the Kentriodontids}

Our analysis suggests that all the species of kentriodontids form a monophyletic group. Although the monophyly of the kentriodontids has been proposed in some earlier studies (e.g., Barnes, 1978, 1985; Muizon, 1988a), the intergeneric and interspecific relationships therein proposed for the members of this family are both different from our results (fig. 1). Here we suggest that kentriodontids are divided into two monophyletic subgroups (fig. 13). The first subgroup includes Kampholophos, Wimahl, 'Rudicetus', and Kentriodon, while the second subgroup includes Delphinodon, Tagicetus, Macrokentriodon, Liolithax, Hadrodelphis, Pithanodelphis, Lophocetus, and Atocetus. The 50\% majority rule consensus tree (fig. 13) shows agreements with Lambert et al. (2017), Peredo, Uhen \& Nelson (2018) and Kimura \& Hasegawa (2019) at least as regards the former subgroup (fig. 1). In this regard, the monophyly of the former subgroup is considered to be robust. On the other hand, other kentriodontids had been subdivided into five paraphyletic or polyphyletic groups by Lambert et al. (2017) and Peredo, Uhen \& Nelson (2018). Particularly, both of their unconstrained analyses suggested that a kentriodontid species Liolithax was recognized as a sister taxon to the Lipotidae, meaning that it was recognized to be more closely related to Iniidae + Pontoporiidae than other 'kentriodontids'.

Particularly, the result of our phylogenetic analysis is somewhat similar to that obtained by Tanaka et al. (2017), but the interrelationships of the Delphinida (Lipotidae + Inioidea + Kentriodontidae, as redefined herein + crown Delphinoidea) are different in the two studies (fig. 1). As regards Delphinida, the interrelationships of the crown Delphinoidea (Delphinidae + Monodontidae + Phocoenidae), including the extinct taxa, also recall those recovered by Tanaka et al. (2017), but the sister group relationships among Delphinida (Lipotidae + Inioidea + Kentriodontidae) are different. Tanaka et al. (2017) included in their analysis only three kentriodontids and suggested that they formed a paraphyletic group. These three kentriodontids were located basal to the crown Delphinoidea.

As mentioned above, we performed our phylogenetic analysis by applying a tree constraint based on molecular evidence by McGowen, Spaulding \& Gatesy (2009), McGowen et al. (2011) and McGowen et al. (2020) (fig. 1) as was also the case for the analysis by Tanaka et al. (2017). Lambert et al. (2017) performed their phylogenetic analyses both with a tree 
578 constraint based on molecular evidence and without such a tree constraint, and they preferred 579 their unconstrained tree as a result from their multiple analyses. The study by Lambert et al.

580 (2017) was so comprehensive that it might be the reason why the molecular evidence had not 581 been used in later studies on the phylogeny of the Delphinida including the kentriodontids (e.g.,

582 Peredo, Uhen \& Nelson, 2018; Kimura \& Hasegawa, 2019, 2020). Molecular phylogenetics is 583 now widely accepted for reconstructing the phylogenetic relationships of organisms, but its 584 results are sometimes different from analyses based only on morphological data. Although many 585 of the aforementioned studies (e.g., Lambert et al., 2017; Peredo, Uhen \& Nelson, 2018; 586 Kimura \& Hasegawa, 2019) chose the total evidence approach (parsimony analysis based both 587 on molecular and morphological evidence) for their analyses, the resulting relationships they 588 suggested are different from that of the analyses based on molecular data only in regard to the 589 extant species (McGowen, Spaulding \& Gatesy, 2009; McGowen et al., 2011; McGowen et al., 590 2020; Geisler et al., 2011; Post et al., 2017; Lambert et al., 2018a, 2020).

Because of relatively low bootstrap values for the result of our phylogenetic analysis, the morphological evidence for the monophyly of kentriodontids is still not robust in support. However, it should be emphasized that the result of our parsimony analysis with tree constraint by molecular evidence is consequently no contradiction with molecular phylogenetics for the extant species for the first time.

599

600

601

602

603

604

605

606

607

608

609

610

611

612

613

\section{Diversifications of Delphinida Based on the Ear Bones}

At the time of the evolution and diversification of Delphinida, including Lipotidae, Inioidea, monophyletic kentriodontids, and crown Delphinoidea, seven out of 18 synapomorphies are considered as evolutionary changes of periotic and tympanic bulla features. These changes could be interpreted as the result of evolutionary innovation, for example the potential specialization of their echolocation abilities among odontocetes (Gutstein et al., 2014; Churchill et al., 2016). These characters are the following: the processus muscularis of the malleus is sub-equal or longer than the manubrium (Chr. 237), the articulation of the anterior process of the periotic with the squamosal is absent (Chr. 253), the anterior bullar facet is absent (Chr. 254), the dorsal surface of the periotic is nearly flat (Chr. 260), the foramen singulare forms a shared recess with the spiral cribriform tract, the transverse crest that separates it from the proximal opening of the facial nerve canal is low, and the proximal opening of the facial nerve canal is within the internal acoustic meatus (Chr. 269), the aperture for the cochlear aqueduct is smaller than the aperture for the vestibular aqueduct (Chr. 272), and the dorsal margin of the involucrum of the tympanic bulla is excavated just anterior to the posterior process (Chr. 317). Furthermore, the node uniting the kentriodontids and the crown delphinoids is supported by 11 synapomorphies, six of which

614

615

616

617 regarding auditory specializations, namely: the apex of the anterior process of the periotic is thickened by the prominent dorsal tubercle that gives to this apex a rectangular section on the plane of the body of the periotic (Chr. 239), the contact of the anterior process of the petrosal with a portion of the ectotympanic bulla anterior to the accessory ossicle is absent (Chr. 249), the periotic articulates with the squamosal along the hiatus epitympanicus and adjacent regions on 
618 the posterior process (Chr. 286), the posterior process of the periotic is long (Chr. 292), the 619 lateral furrow of the tympanic bulla is present as a shallow groove (Chr. 303), and the ventral 620 margin of the tympanic bulla is concave in lateral view (Chr. 307). Compared with other 621 odontocetes, the ear bones of delphinidans are highly specialized (e.g., Fraser \& Purves, 1960;

622 Gutstein et al., 2014), and kentriodontids share a number of tympanoperiotic apomorphies with 623 the crown delphinoids rather than with inioids (see also Gutstein et al., 2014). These

624 morphological changes of the periotic and tympanic bulla in the Delphinida are thought to have 625 been emphasized by their diversification or specialization of functional relationships between the 626 periotic, tympanic bulla, and nearby portion of the skull during the process of the acquisition of 627 much higher frequency (i.e., ultrasonic) sound hearing abilities (e.g., Gutstein et al., 2014; Ary, 628 2017), and sound reception mechanism (Cranford, Krysl \& Amundin, 2010). These changes 629 might also have allowed delphinidans to diversify their abilities of echolocation, such as narrow630 band and bimodal sound structure (e.g., Churchill et al., 2016; Mourlam \& Orliac, 2017) and 631 habitat preferences (Costeur et al., 2018). However, the direct relationship of the above structural 632 changes of tympanoperiotics and resulting functional innovations are still uncertain (Gutstein et 633 al., 2014). Therefore, relationships between these morphological and functional changes should 634 be tested through further work. Nevertheless, 13 tympanoperiotic characters out of 29 characters 635 as synapomorphies for the Delphinida still indicate their specialization and innovation of hearing 636 abilities.

637 Among delphinidans, kentriodontids exhibited a high diversity during the Miocene 638 (Ichishima et al., 1995, Marx, Lambert \& Uhen, 2016, Plate 16a). Based on published records 639 (Ichishima et al., 1995; Ichishima, 1995; Dawson, 1996a; Dawson, 1996b; Bianucci, 2001; 640 Kazár, 2005; Kazár \& Grigorescu, 2005; Lambert, Estevens \& Smith, 2005; Kazár, 2006; 641 Whitmore \& Kaltenbach, 2008; Kazár \& Hampe, 2014; Salinas-Márquez et al., 2014; Peredo, 642 Uhen \& Nelson, 2018; Kimura \& Hasegawa, 2019); all 31 taxa that can be recognized as 643 kentriodontids are known in the Miocene; 6 in the early Miocene, 19 in the middle Miocene and 6446 in the late Miocene. Conversely, crown delphinoids and inioids do not appear until the end of 645 the middle Miocene (Murakami et al., 2014; Murakami, 2016; Kimura and Hasegawa, 2020). In 646 this regard, kentriodontids geochronologically form a first diverse group within the delphinidans, 647 unique for the modifications of their ear bones within the odontocetes. Considering the high ratio 648 of morphological changes observed in their tympanoperiotics and their high species richness, the 649 specializations of their hearing apparatus in kentriodontids probably resulted in their great 650 diversification during the period between the early and middle Miocene.

651

652 Institutional abbreviations

653 NMHF Ninohe Museum of History and Folklore, Ninohe City, Iwate, Japan.

654 NMNS-PV Fossil vertebrate collections at the National Museum of Nature and Science,

655

656

657 Tsukuba, Japan.

NSMT-M Marine mammal collections at the National Museum of Nature and Science, Tsukuba, Japan. 
658

659

660

661

662

663

664

665

666

667

668

669

670

671

672

673

674

675

676

677

678

679

680

681

682

683

684

685

686

687

688

689

690

691

692

693

694

695

696

697

\section{Acknowledgements}

We wish to thank K. Sugawara (then NMHF), Y. Seki (NMHF) and Y. Inaba (NMHF) for permitting us to describe NMHF 999. We also thank Y. Tajima (NMNS), T. Kimura (GMNH) for providing access to the collections under their care. Our thanks also go to Y. Tajima and T.K. Yamada (NMNS), M. Oishi (then Iwate Prefectural Museum), H. Ichishima (Fukui Prefectural Dinosaur Museum) and Y. Yanagisawa (Geological Survey of Japan) for providing useful discussion and advice. We thank K. Sashida (then University of Tsukuba, now Mahidol Univ.) and S. Agematsu (Univ. Tsukuba) for their help during field works. We are grateful to K. Sashida, S. Agematsu, K. Tanaka (Univ. Tsukuba), and Yasunari Shigeta (NMNS/Univ. Tsukuba) for their useful advice, discussions and generous encouragement during the course of this study. The manuscript has been greatly improved by careful attention to detail and extensive comments from PeerJ editor B. Hedrick, reviewers N. Pyenson, O. Lambert and an anonymous reviewer. We appreciate their efforts very much.

\section{References}

Abel O. 1905. Les Odontocètes du Boldérien (Miocène supérieur) des environs d'Anvers. Mémoires du Musée Royal d'Histoire Naturelle de Belgique 3:1-155.

Ary WJ. 2017. Form, function and phylogeny in the cetacean ear complex. San Diego State University, ProQuest Dissertations Publishing 10689605.

Barnes LG. 1978. A review of Lophocetus and Liolithax and their relationships to the delphinoid family Kentriodontidae (Cetacea: Odontoceti). Bulletin of the Natural History Museum of Los Angeles County 28:1-35.

Barnes LG. 1985. The Late Miocene dolphin Pithanodelphis Abel, 1905 (Cetacea, Kentriodontidae) from California. Contributions in Science, Natural History Museum of Los Angeles County 367:1-27

Barnes LG, Mitchell ED. 1984. Kentriodon obscurus (Kellogg, 1931), a fossil dolphin (Mammalia: Kentriodontidae) from the Miocene Sharktooth Hill Bonebed in California. Contributions in Science, Natural History Museum of Los Angeles County 353:1-23.

Bianucci G. 2001. A new genus of kentriodontid (Cetacea: Odontoceti) from the Miocene of South Italy. Journal of Vertebrate Paleontology 21:573-577. DOI: 10.1671/02724634(2001)021[0573:ANGOKC]2.0.CO;2.

Chinzei K. 1966. Younger Tertiary geology of the Mabechi River valley, northeast Honshu, Japan. Journal of the Faculty of Science, the University of Tokyo. Sect. II 16:161-208.

Churchill M, Martinez-Caceres M, de Muizon C, Mnieckowski J, Geisler JH. 2016. The origin of high-frequency hearing in whales. Current Biology 26:2144-2149. DOI: 10.1016/j.cub.2016.06.004.

Cope ED. 1867. An addition to the vertebrate fauna of the Miocene period, with a synopsis of the extinct cetacea of the United States. Proceedings of the Academy of Natural Sciences of Philadelphia 19:138-156. 
698 Costeur L, Grohé C, Aguirre-Fernández G, Ekdale E, Schulz G, Müller B, Mennecart B. 2018. 699 The bony labyrinth of toothed whales reflects both phylogeny and habitat preferences.

$700 \quad$ Scientific Reports 8. DOI: 10.1038/s41598-018-26094-0.

701 Cranford TW, Krysl P, Amundin M. 2010. A new acoustic portal into the odontocete ear and 702 vibrational analysis of the tympanoperiotic complex. PLoS ONE 5. DOI:

$703 \quad$ 10.1371/journal.pone.0011927.

704 Dawson SD. 1996a. A description of the skull and postcrania of Hadrodelphis calvertense

705

706

707

708

709

710

711

712

713

714

715

716

717

718

719

720

721

722

723

724

725

726

727

728

729

730

731

732

733

734

735

736

737 Kellogg 1966, and its position within the Kentriodontidae (Cetacea; Delphinoidea). Journal of Vertebrate Paleontology 16:125-134. DOI: 10.1080/02724634.1996.10011290

Dawson SD. 1996b. A new kentriodontid dolphin (Cetacea; Delphinoidea) from the middle Miocene Choptank Formation, Maryland. Journal of Vertebrate Paleontology 16:135-140. DOI: 10.1080/02724634.1996.10011291.

Fraser FC, Purves PE. 1960. Hearing in Cetaceans. Evolution of the accessory air sacs and the structure and function of the outer and middle ear in recent cetaceans. Bulletin of the British Museum (Natural History) Zoology 7:1-140, 53 pls. frontis.

Gatesy J, Geisler JH, Chang J, Buell C, Berta A, Meredith RW, Springer MS, McGowen MR. 2013. A phylogenetic blueprint for a modern whale. Molecular Phylogenetics and Evolution 66:479-506. DOI: 10.1016/j.ympev.2012.10.012.

Geisler JH, Godfrey SJ, Lambert O. 2012. A new genus and species of late Miocene inioid (Cetacea, Odontoceti) from the Meherrin River, North Carolina, U.S.A. Journal of Vertebrate Paleontology 32:198-211. DOI: 10.1080/02724634.2012.629016.

Geisler JH, McGowen MR, Yang G, Gatesy J. 2011. A supermatrix analysis of genomic, morphological, and paleontological data from crown Cetacea. BMC Evolutionary Biology 11. DOI: 10.1186/1471-2148-11-112.

Goloboff PA, Catalano SA. 2016. TNT version 1.5, including a full implementation of phylogenetic morphometrics. Cladistics 32:221-238. DOI: 10.1111/cla.12160

Goloboff PA, Farris JS, Nixon KC. 2008. TNT, a free program for phylogenetic analysis. Cladistics 24:774-786. DOI: 10.1111/j.1096-0031.2008.00217.x.

Gutstein CS, Figueroa-Bravo CP, Pyenson ND, Yury-Yañez RE, Cozzuol MA, Canals M. 2014. High frequency echolocation, ear morphology, and the marine-freshwater transition: A comparative study of extant and extinct toothed whales. Palaeogeography, Palaeoclimatology, Palaeoecology 400:62-74. DOI: 10.1016/j.palaeo.2014.01.026.

Ichishima H. 1995. A new fossil kentriodontid dolphin (Cetacea; Kentriodontidae) from the Middle Miocene Takinoue Formation, Hokkaido, Japan. The Island Arc 3, 473-485 (for 1994). DOI: 10.1111/j.1440-1738.1994.tb00126.x

Ichishima H, Barnes LG, Fordyce RE, Kimura M, Bohaska DJ. 1995. A review of kentriodontine dolphins (Cetacea; Delphinoidea; Kentriodontidae): Systematics and biogeography. Island Arc 3:486-492 (for 1994). DOI: 10.1111/j.1440-1738.1994.tb00127.x.

Ichishima H. 2016. The ethmoid and presphenoid of cetaceans. Journal of Morphology 277:1661-1674. 
738

739

740

741

742

743

744

745

746

747

748

749

750

751

752

753

754

755

756

757

758

759

760

761

762

763

764

765

766

767

768

769

770

771

772

773

774

775

776

777

Irizuki T, Matsubara T. 1994. Vertical changes of depositional environments of the Lower to Middle Miocene Kadonosawa Formation based on analyses of fossil ostracode faunas. The Journal of the Geological Society of Japan 100:136-149. [Japanese with English abstract] Kamemaru A, Matsubara T, Irizuki T. 1995. Foraminiferal assemblage in the Lower to Middle Miocene Kadonosawa Formation at the type locality, Iwate Prefecture. Abstract of the 102nd Annual Meeting of the Geological Society of Japan:93. [Japanese]

Kazár E, Hampe O. 2014. A new species of Kentriodon (Mammalia, Odontoceti, Delphinoidea) from the middle/late Miocene of Groß Pampau (Schleswig-Holstein, North Germany). Journal of Vertebrate Paleontology 34:1216-1230. DOI:10.1080/02724634.2014.85734

Kazár E. 2005. A new kentriodontid (Cetacea: Delphinoidea) from the Middle Miocene of Hungary, Fossil Record 8:53-73. DOI:10.1002/mmng.200410004.

Kazár E. 2006. Odontocete periotics (Mammalia: Cetacea) from the Carpathian Basin, middle Miocene (Badenian and Sarmatian Stages), including the Vienna Basin, Austria. Beitrage zur Palaontologie 30:269-292.

Kazár E, Grigorescu D. 2005. Revision of Sarmatodelphis moldavicus Kirpichnikov, 1954 (Cetacea: Delphinoidea), from the Miocene of Kishinev, Republic of Moldavia. Journal of Vertebrate Paleontology 25:929-935.

Kellogg A. R. 1927. Kentriodon pernix, a Miocene porpoise from Maryland. Proceedings of the United States National Museum 69:1-55.

Kellogg R. 1931. Pelagic mammals from the Temblor Formation of the Kern River region, California. Proceedings of the California Academy of Sciences XIX:217-397.

Kimura T, Hasegawa Y. 2019. A new species of Kentriodon (Cetacea, Odontoceti, Kentriodontidae) from the Miocene of Japan. Journal of Vertebrate Paleontology 39:1-14. DOI: $10.1080 / 02724634.2019 .1566739$.

Kimura T, Hasegawa Y. 2020. Norisdelphis annakaensis, A new Miocene delphinid from Japan. Journal of Vertebrate Paleontology:e1762628. DOI: 10.1080/02724634.2020.1762628.

Lambert O, Auclair C, Cauxeiro C, Lopez M, Adnet S. 2018a. A close relative of the Amazon river dolphin in marine deposits: a new Iniidae from the late Miocene of Angola. PeerJ 6:e5556 https://doi.org/10.7717/peerj.5556

Lambert O, Bianucci G, Urbina M, Geisler JH. 2017. A new inioid (Cetacea, Odontoceti, Delphinida) from the Miocene of Peru and the origin of modern dolphin and porpoise families. Zoological Journal of the Linnean Society 179:919-946. DOI: 10.1111/zoj.12479.

Lambert O, Collareta A, Benites-Palomino A, Di Celma C, de Muizon C, Urbina M, Bianucci G. 2020. A new small, mesorostrine inioid (Cetacea, Odontoceti, Delphinida) from four upper Miocene localities in the Pisco Basin, Peru. Papers in Palaeontology:spp2.1332. DOI: $10.1002 / \mathrm{spp} 2.1332$.

Lambert O, Estevens M, Smith R. 2005. A new kentriodontine dolphin from the middle Miocene of Portugal. Acta Palaeontologica Polonica 50:239-248.

Lambert O, Muizon C de, Malinverno E, Di Celma C, Urbina M, Bianucci G. 2018b. A new odontocete (toothed cetacean) from the early Miocene of Peru expands the morphological

Peer) reviewing PDF | (2020:08:52427:2:0:CHECK 17 Jan 2021) 
778

779

780

781

782

783

784

785

786

787

788

789

790

791

792

793

794

795

796

797

798

799

800

801

802

803

804

805

806

807

808

809

810

811

812

813

814

815

disparity of extinct heterodont dolphins. Journal of Systematic Palaeontology 16:981-1016. DOI: $10.1080 / 14772019.2017 .1359689$.

Marx FG, Lambert O, Uhen MD. 2016. Cetacean Paleobiology, Wiley Blackwell, Topics in Paleobiology, 319. DOI:10.1002/9781118561546

McGowen MR, Montgomery SH, Clark C, Gatesy J. 2011. Phylogeny and adaptive evolution of the brain-development gene microcephalin (MCPH1) in cetaceans. BMC Evolutionary Biology 11. DOI: 10.1186/1471-2148-11-98.

McGowen MR, Spaulding M, Gatesy J. 2009. Divergence date estimation and a comprehensive molecular tree of extant cetaceans. Molecular Phylogenetics and Evolution 53:891-906. DOI: 10.1016/j.ympev.2009.08.018.

McGowen MR, Tsagkogeorga G, Álvarez-Carretero S, Dos Reis M, Struebig M, Deaville R, Jepson PD, Jarman S, Polanowski A, Morin PA, Rossiter SJ. 2020. Phylogenomic resolution of the cetacean tree of life using target sequence capture. Systematic Biology 69:479-501. DOI: 10.1093/sysbio/syz068.

Mead JG, Fordyce RE. 2009. The therian skull: a lexicon with emphasis on the odontocetes. Smithsonian Contributions to Zoology:1-249. DOI: 10.5479/si.00810282.627.

Mourlam MJ, Orliac MJ. 2017. Infrasonic and ultrasonic hearing evolved after the emergence of modern whales. Current Biology 27:1776-1781.e9. DOI: 10.1016/j.cub.2017.04.061.

Muizon C de. 1988a. Les relations phylogénétiques des Delphinida (Cetacea, Mammalia). Annales de Paléontologie 74:159-227.

Muizon C de. 1988b. Les vertébrés fossiles de la Formation Pisco (Pérou). Troisième partie: Les Odontocètes (Cetacea, Mammalia) du Miocène. Travaux de l'Institut Français d'Etudes Andines 78:1-244.

Murakami, M. 2016. A new extinct inioid (Cetacea, Odontoceti) from the Upper Miocene Senhata Formation, Chiba, central Japan: the first record of Inioidea from the North Pacific Ocean." Paleontological Research 20(3):207-225.

Murakami M, Shimada C, Hikida Y, Hirano H. 2012. Two new extinct basal phocoenids (Cetacea, Odontoceti, Delphinoidea), from the upper Miocene Koetoi Formation of Japan and their phylogenetic significance. Journal of Vertebrate Paleontology 32:1172-1185. DOI: 10.1080/02724634.2012.694337.

Murakami M, Shimada C, Hikida Y, Hirano H. 2014. Asymmetrical basal delphinoid skull from the upper lower Miocene Yamato Formation of Hokkaido, northern Japan: implications on evolution of cranial asymmetry and symmetry in Odontoceti. Paleontological Research 18:134-149. DOI: 10.2517/2014pr013.

Oishi M, Hasegawa Y, Yanagisawa Y, Matsubara T, Kikuchi H, Komori K, Kawamorita H. 1999. Miocene kentriodontid dolphins from Ninohe and Ichinohe, Iwate Prefecture, Japan. Abstract of the 1999 Annual Meeting of the Palaeontological Society of Japan:55. (January 29 - 31, 1999 at Sendai, Japan, Palaeontological Society of Japan). [Japanese] 
816 Oishi M, Kawakami T. 1984. A new occurrence of desmostylian molar from the Miocene 817 Kadonosawa Formation, Nisatai, Ninohe-City, Iwate Prefecture. The Journal of the

818 Geological Society of Japan 90(1):55-58. [Japanese]

819 Peredo CM, Uhen MD, Nelson MD. 2018. A new kentriodontid (Cetacea: Odontoceti) from the

820

821

822

823

824

825

826

827

828

829

830

831

832

833

834

835

836

837

838

839

840

841

842

843

844

845

846

847

848

849

850

851

852

853

854

855

Kentriodontidae. Journal of Vertebrate Paleontology 38. DOI: 10.1080/02724634.2017.1411357.

Post K, Louwye S, Lambert O. 2017. Scaldiporia vandokkumi, a new pontoporiid (Mammalia, Cetacea, Odontoceti) from the Late Miocene to earliest Pliocene of the Westerschelde estuary (The Netherlands). PeerJ 5:e3991 https://doi.org/10.7717/peerj.3991

Rensberger JM. 1969. A new iniid cetacean from the Miocene of California. University of California publications in geological sciences 82:43.

Salinas-Márquez FM, Barnes LG, Flores-Trujillo JG, Aranda-Manteca FJ. 2014. A species of fossil dolphin (Cetacea; Delphinoidea; Kentriodontidae) from the Middle Miocene of Baja California. Boletin de la Sociedad Geologica Mexicana 66:145-164. DOI: 10.18268/BSGM2014v66n1a11.

Tanaka Y, Abella J, Aguirre-Fernández G, Gregori M, Fordyce RE. 2017. A new tropical Oligocene dolphin from Montañita/Olón, Santa Elena, Ecuador. PLoS ONE 12:e0188380. DOI: 10.1371/journal.pone.0188380.

Tanaka Y, Fordyce RE. 2014. Fossil dolphin Otekaikea marplesi (Latest Oligocene, New Zealand) expands the morphological and taxonomic diversity of Oligocene cetaceans. PLoS ONE 9. DOI: 10.1371/journal.pone.0107972.

Tanaka Y, Fordyce RE. 2016. Papahu-like fossil dolphin from Kaikoura, New Zealand, helps to fill the Early Miocene gap in the history of Odontoceti. New Zealand Journal of Geology and Geophysics 59:551-567. DOI: 10.1080/00288306.2016.1211540.

True FW. 1912. Description of a new fossil porpoise of the genus Delphinodon from the Miocene Formation of Maryland. Journal of the Academy of Natural Sciences of Philadelphia 2:165-197.

TuZino T, Kudo T, Nakae S, Kondo R, Nishioka Y, Ueki T. 2018. Geology of the Ichinohe district. Quadrangle Series, 1:50,000, Geological Survey of Japan, AIST, 161p. [Japanese with English abstract]

TuZino T, Yanagisawa Y. 2017. Diatom occurrence from the Miocene in the Ichinohe district, northern part of Iwate Prefecture, NE Japan. Bulletin of the Geological Survey of Japan 68:237-258. [Japanese with English abstract]

Whitmore FC, Kaltenbach JA. 2008. Neogene Cetacea of the Lee Creek Phosphate Mine, North Carolina. Virginia Museum of Natural History Special Publication 14:181-269.

Yanagisawa Y, Akiba F. 1998. Refined Neogene diatom biostratigraphy for the northwest Pacific around Japan, with an introduction of code numbers for selected diatom biohorizons. The Journal of the Geological Society of Japan 104:395-414. DOI: 10.5575/geosoc.104.395.

Peer) reviewing PDF | (2020:08:52427:2:0:CHECK 17 Jan 2021) 


\section{Figure 1}

Geographic and geological context of Kentriodon sugawarai locality.

(A) the type locality of Kentriodon sugawarai, sp. nov., holotype, NMHF 999. (B) left, diatom zone and stratigraphic diagram, modified from Tuzino \& Yanagisawa (2017). right, stratigraphic column of the Mabechi River, Ninohe City, Iwate Prefecture, Japan. 
A

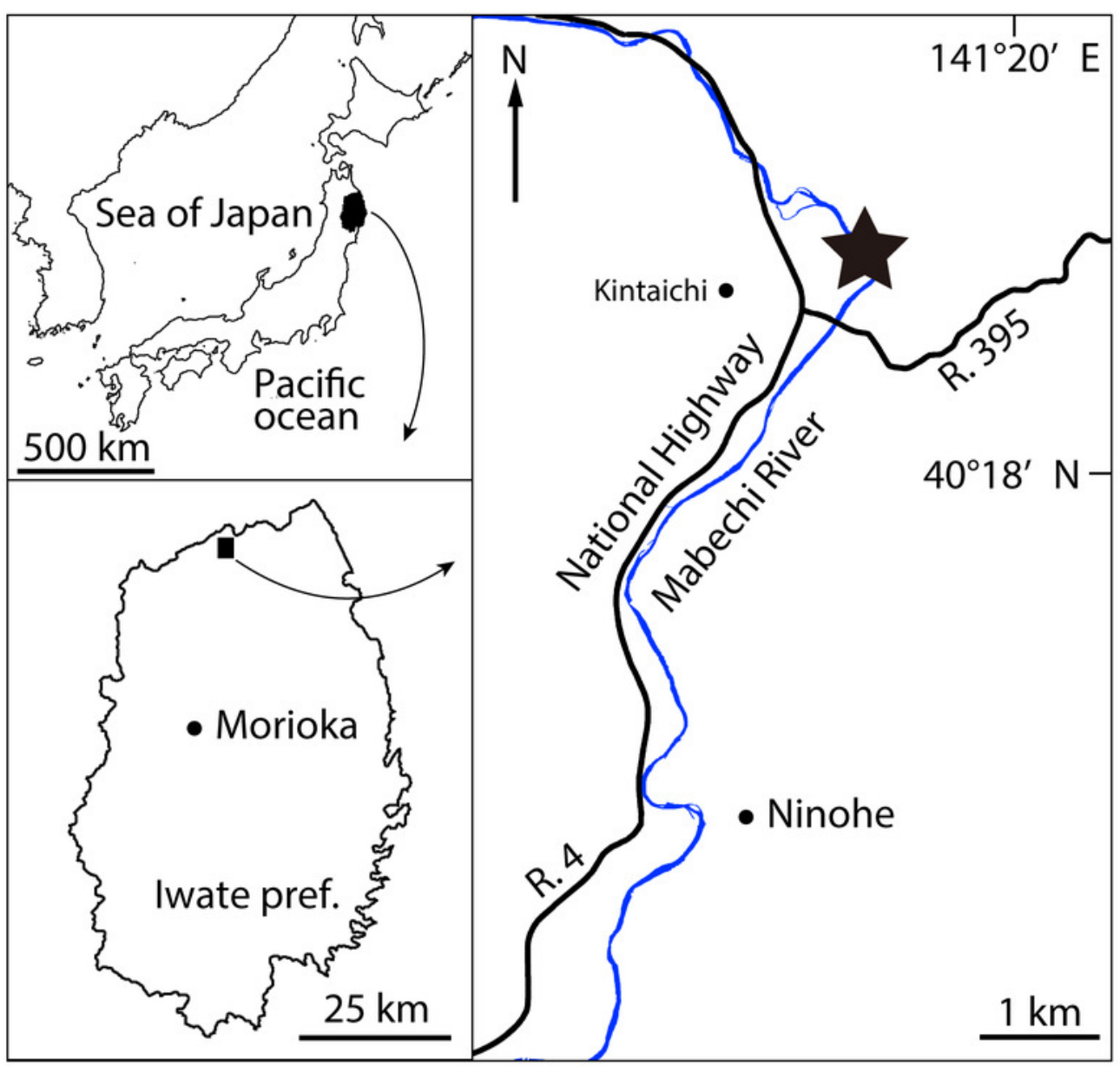

B

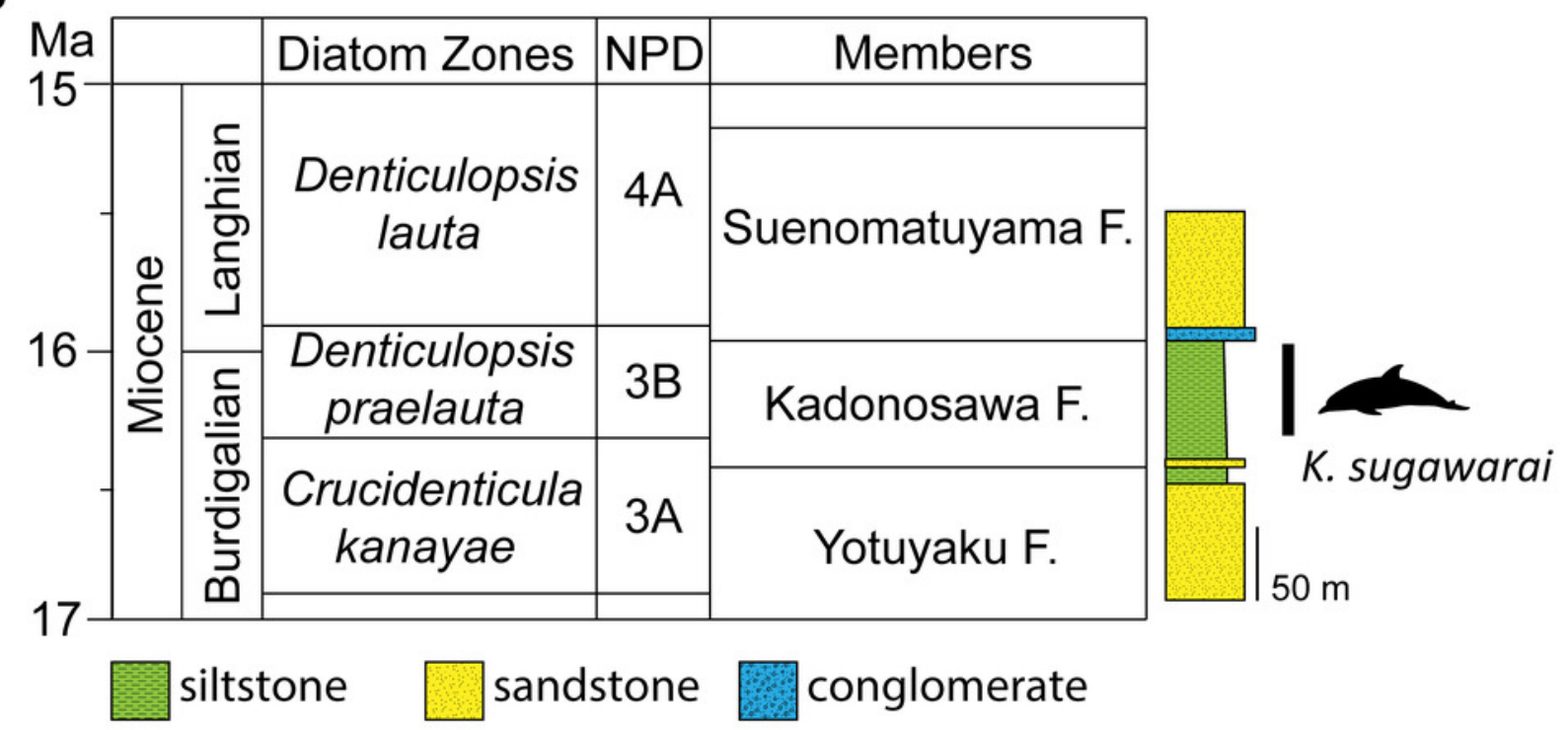


Figure 2

Dorsal views of the skull of Kentriodon sugawarai, sp. nov., holotype, NMHF 999.

(A) photo. (B) corresponding line drawing with anatomical interpretations. Scale bar equals $100 \mathrm{~mm}$. 

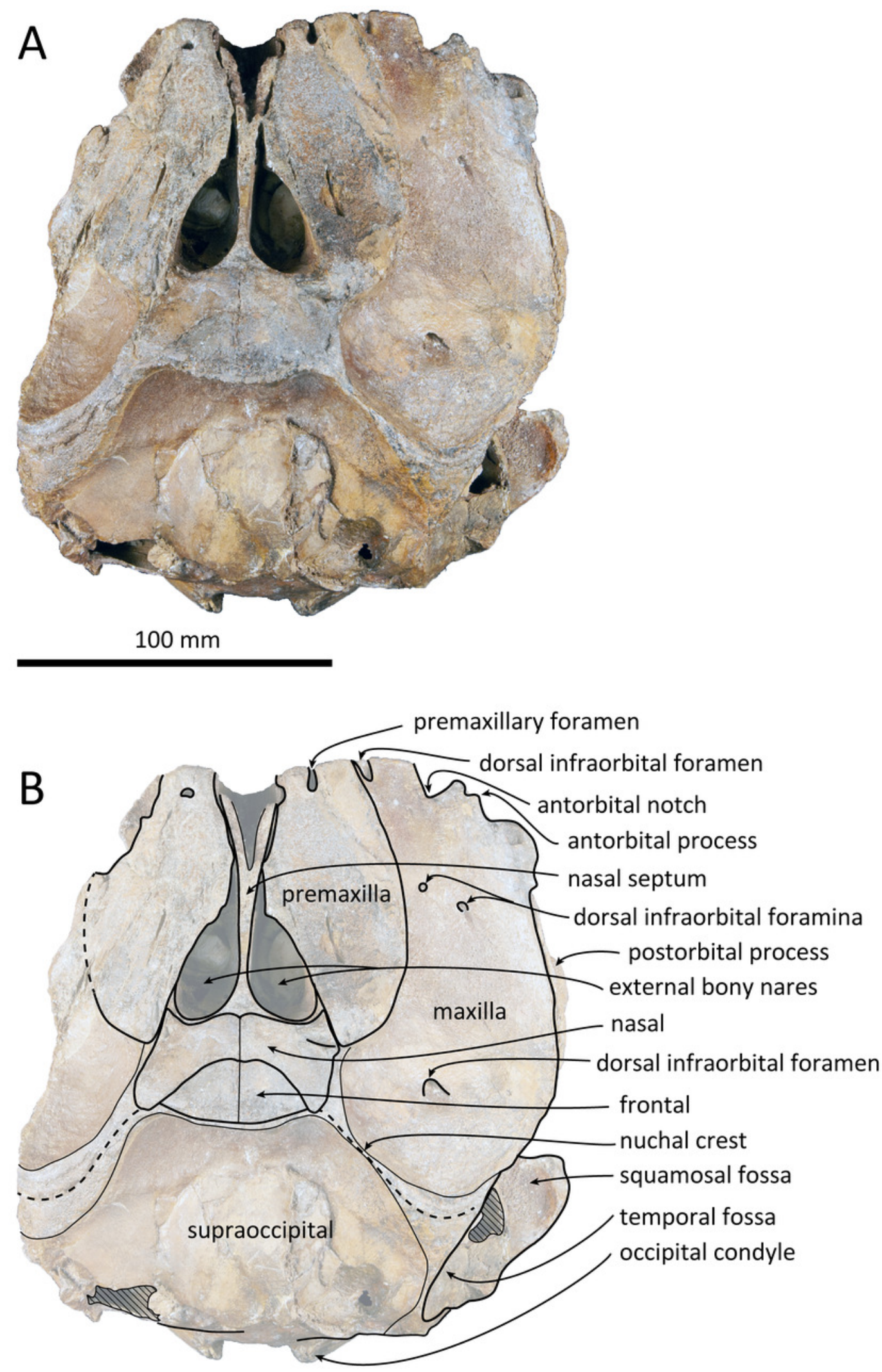
Figure 3

Ventral views of the skull of Kentriodon sugawarai, sp. nov., holotype, NMHF 999.

(A) photo. (B) corresponding line drawing with anatomical interpretations. Scale bar equals $100 \mathrm{~mm}$. 

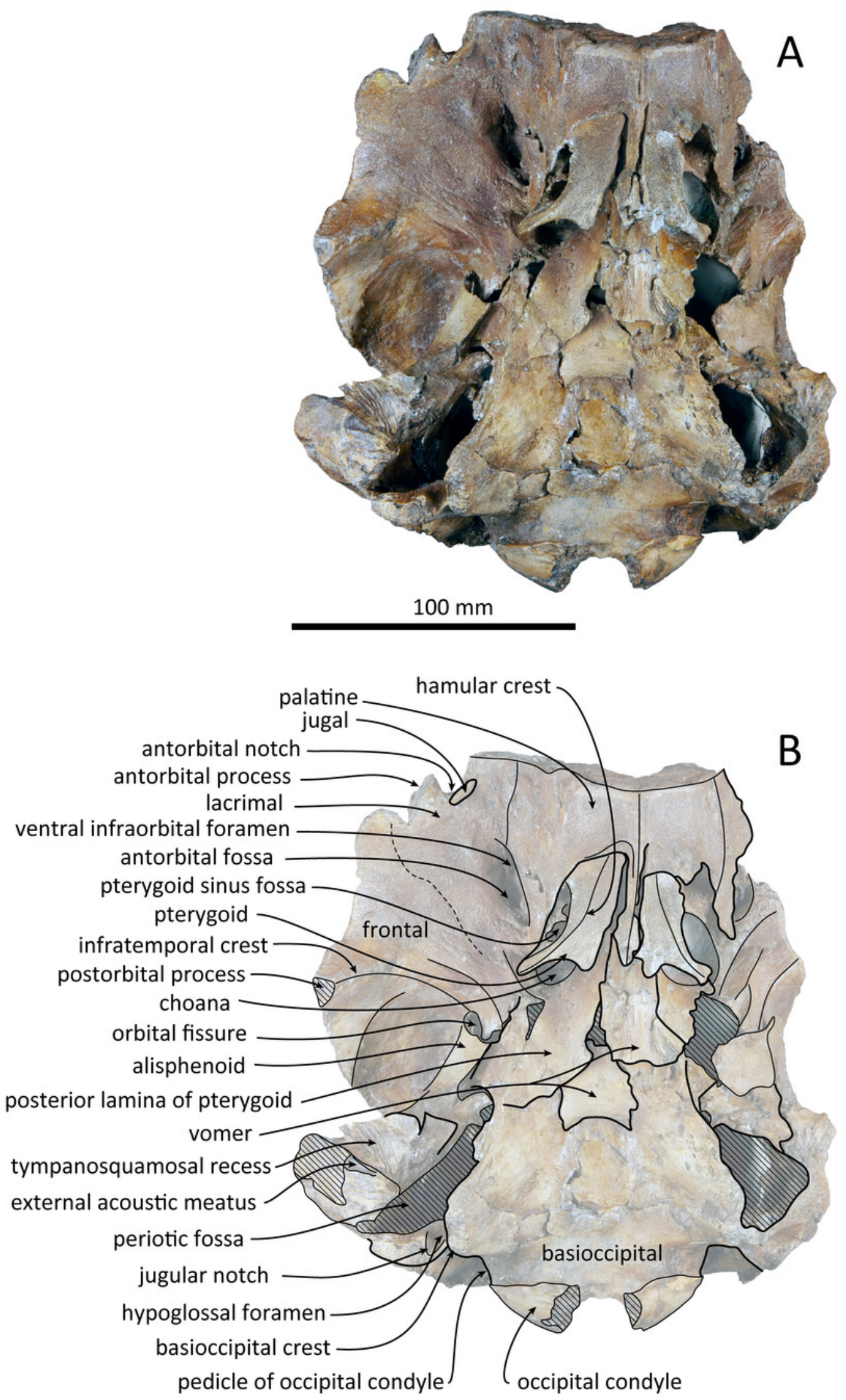


\section{Figure 4}

Right lateral views of the skull of Kentriodon sugawarai, sp. nov., holotype, NMHF 999.

(A) photo. (B) corresponding line drawing with anatomical interpretations. Scale bar equals $100 \mathrm{~mm}$. 

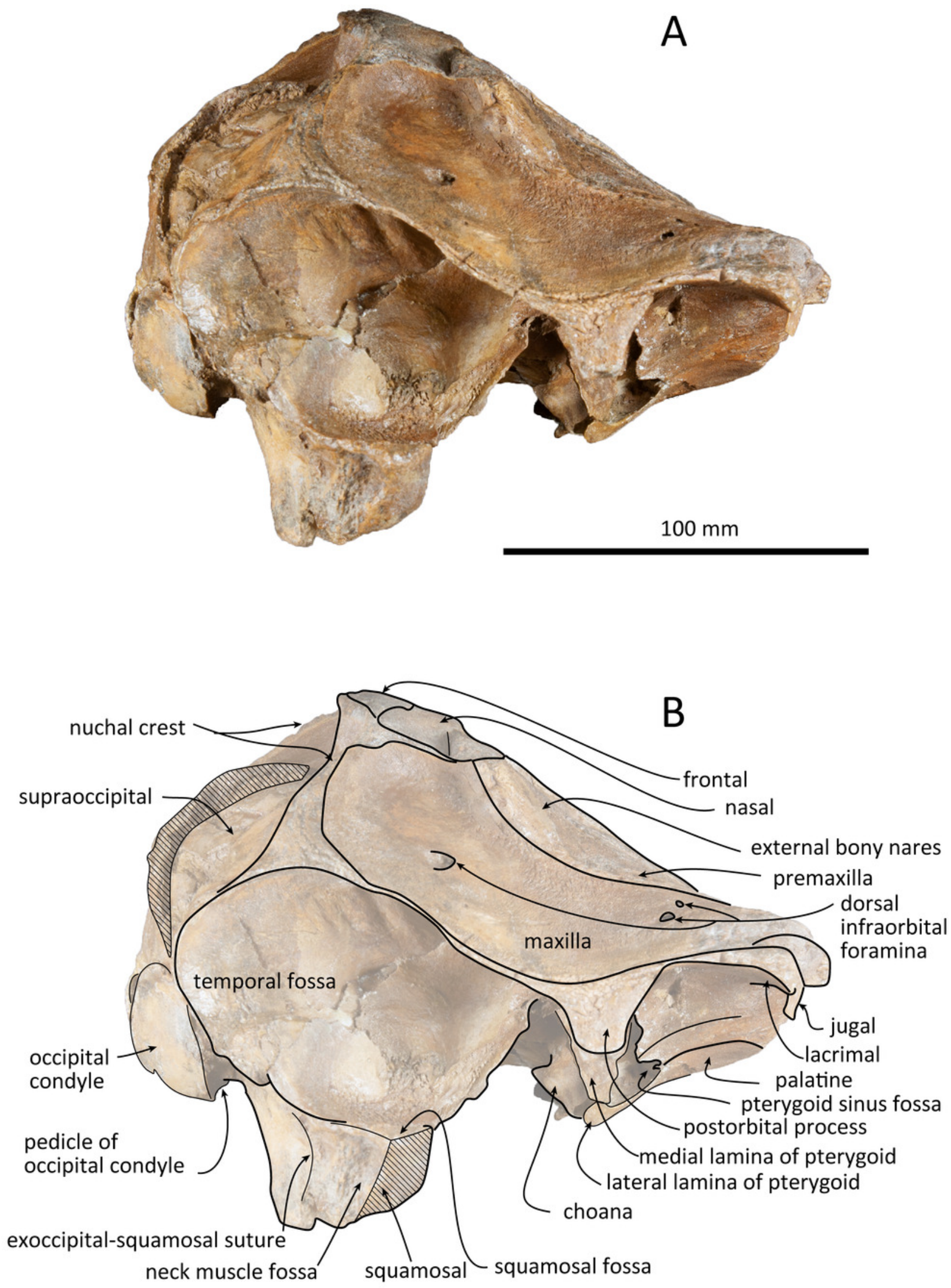
Figure 5

Anterior views of the skull of Kentriodon sugawarai, sp. nov., holotype, NMHF 999.

(A) photo. (B) corresponding line drawing with anatomical interpretations. Scale bar equals $100 \mathrm{~mm}$. 

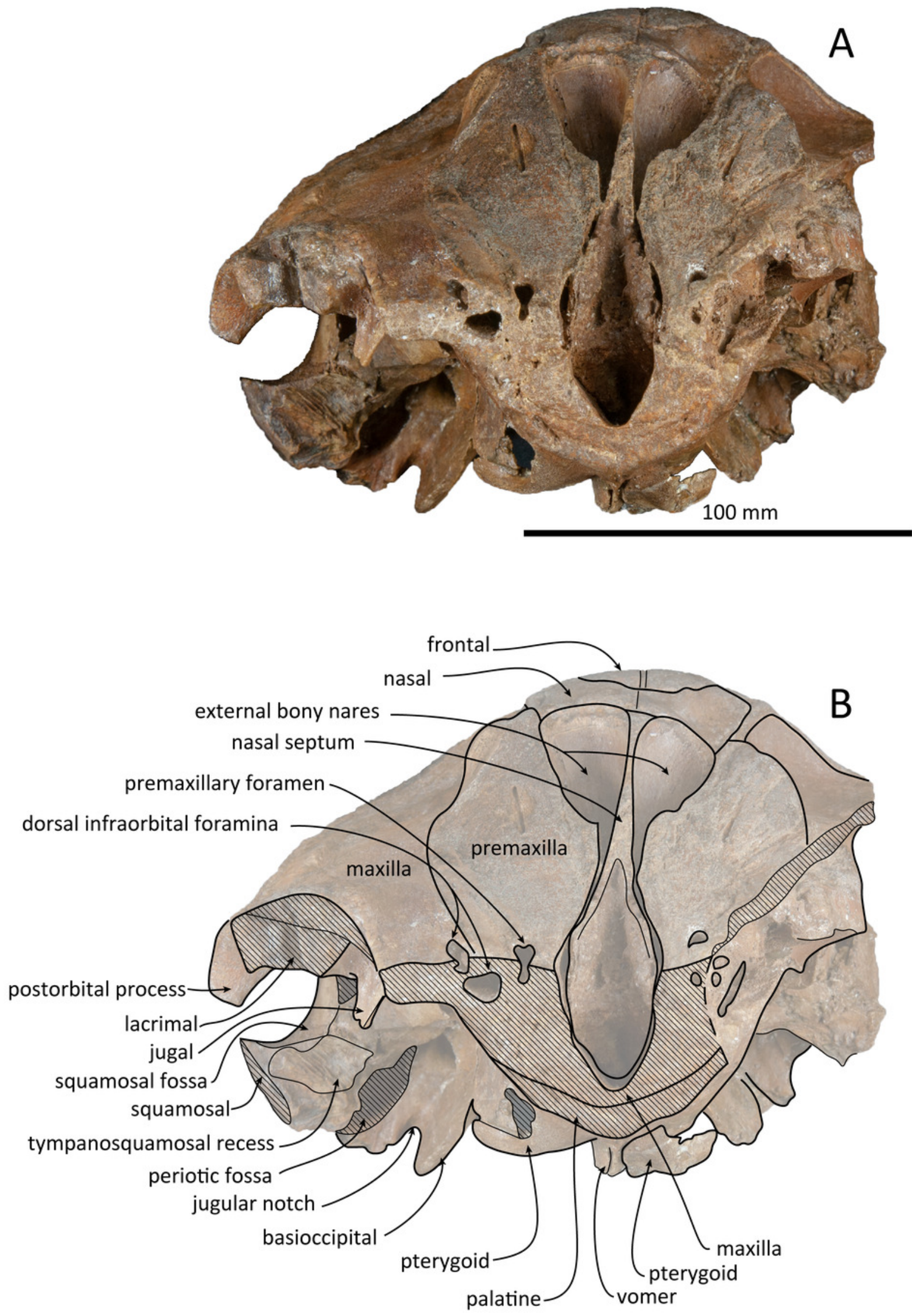
Figure 6

Posterior views of the skull of Kentriodon sugawarai, sp. nov., holotype, NMHF 999.

(A) photo. (B) corresponding line drawing with anatomical interpretations. Scale bar equals $100 \mathrm{~mm}$. 


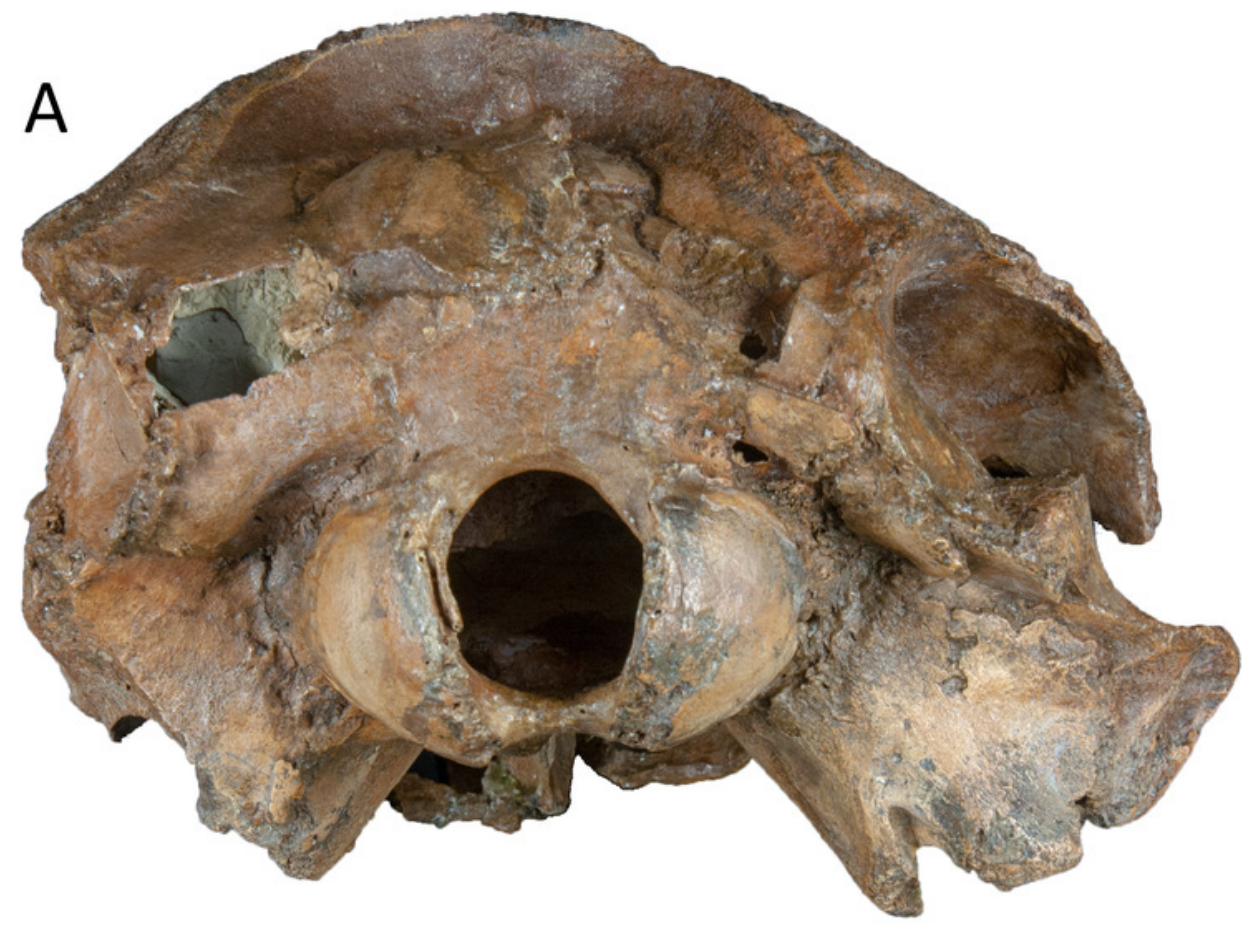

$100 \mathrm{~mm}$

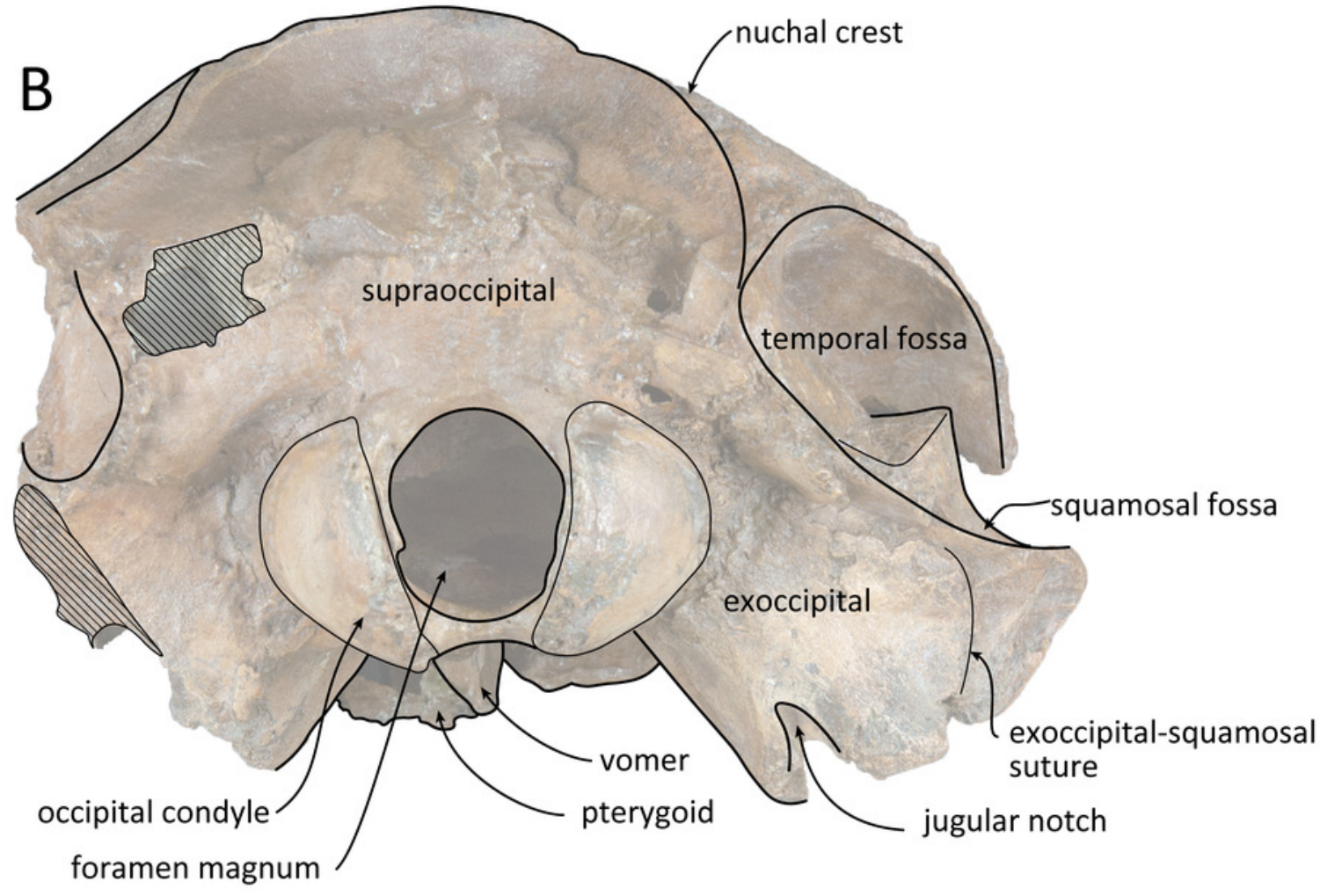


Figure 7

Right periotic of Kentriodon sugawarai, sp. nov., holotype, NMHF 999.

(A) ventral view. (B) dorsal view. (C) medial view. (D) lateral view. (E) anterior view. (F) posterior view. (G) detail view of the internal acoustic meatus. Scale bar equals $20 \mathrm{~mm}$. 

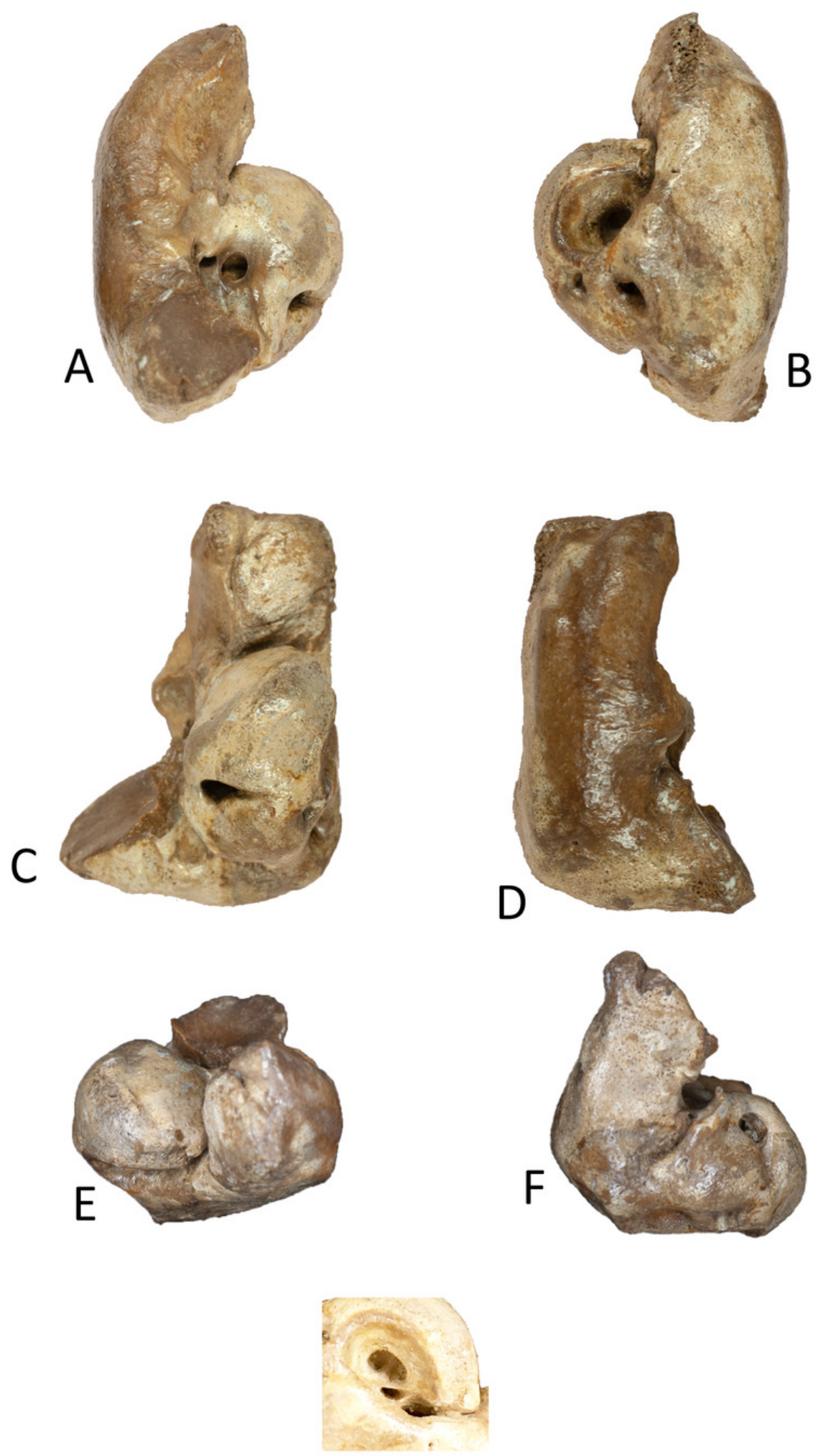

G 
Figure 8

Line drawings of the right periotic of Kentriodon sugawarai, sp. nov., holotype, NMHF 999, with anatomical interpretations.

(A) ventral view. (B) dorsal view. (C) medial view. (D) lateral view. (E) anterior view. (F) posterior view. $(G)$ detail view of the internal acoustic meatus. Scale bar equals $20 \mathrm{~mm}$. 

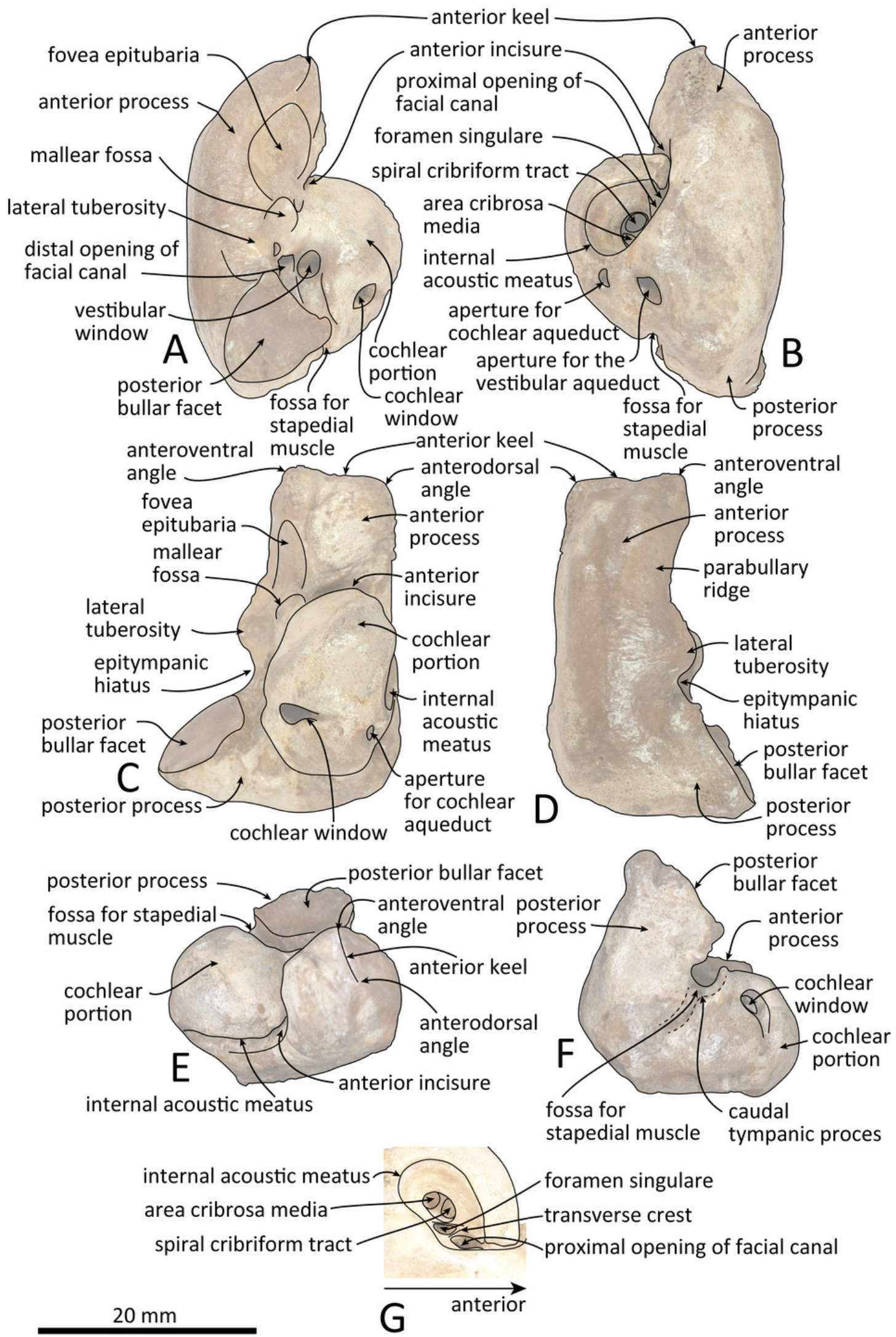
Figure 9

Right tympanic bulla of Kentriodon sugawarai, sp. nov., hototype, NMHF 999.

(A) dorsal view of the posterior process of the tympanic bulla. (B-C) accessory ossicle. (B) dorsal view. (C) ventral view. (D-I), left tympanic bulla. (D) dorsal view. (E) ventral view. (F) lateral view. (G) medial view. (H) anterior view. (I) posterior view. Scale bar equals $20 \mathrm{~mm}$. 

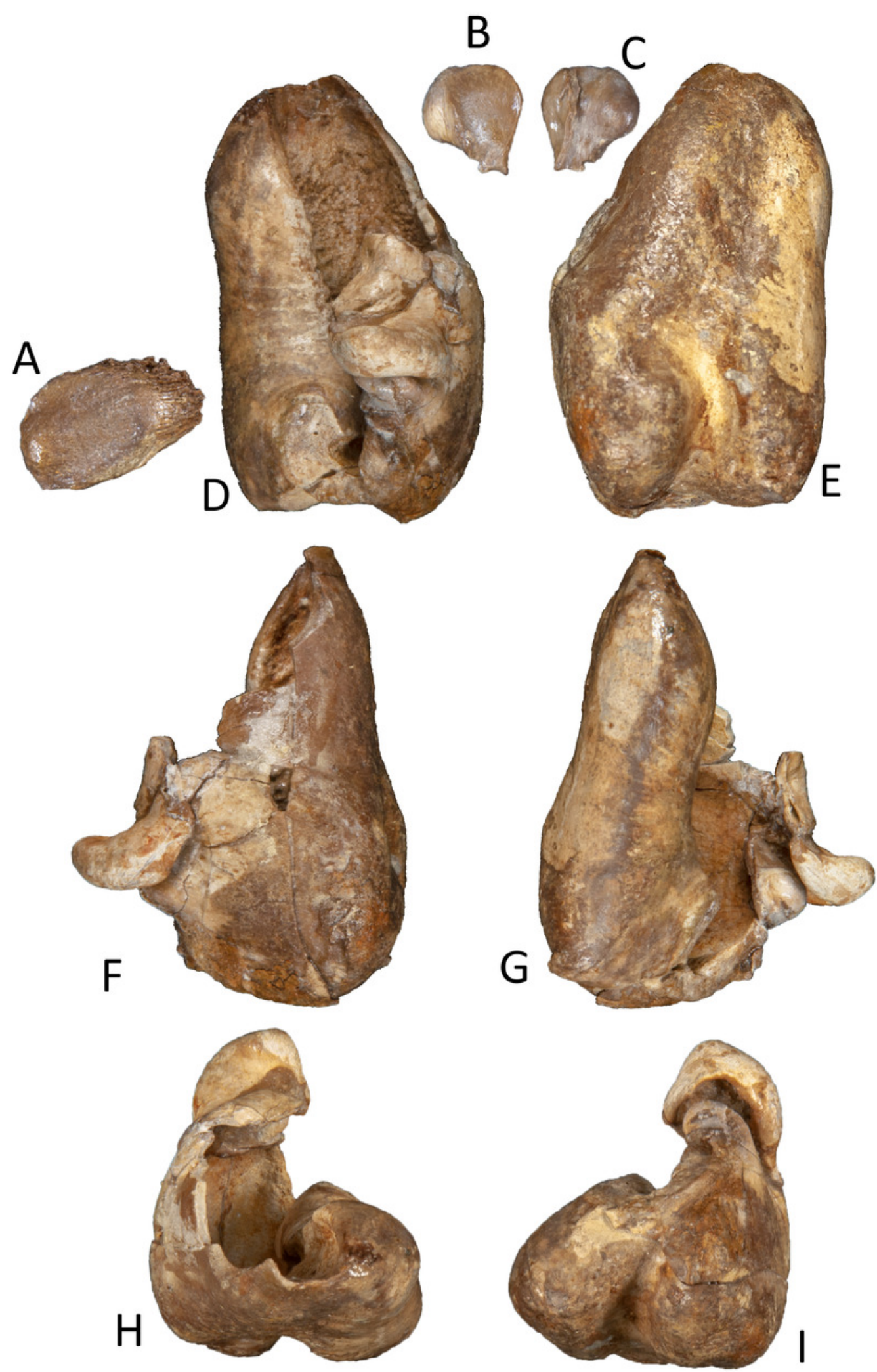

$20 \mathrm{~mm}$ 


\section{Figure 10}

Line drawings of the right tympanic bulla of Kentriodon sugawarai, sp. nov., holotype, NMHF 999.

(A) dorsal view of the posterior process of the tympanic bulla. (B-C) accessory ossicle. (B) dorsal view. (C) ventral view. (D-I) left tympanic bulla. (D) dorsal view. (E) ventral view. (F) lateral view. (G) medial view. (H) anterior view. (I) posterior view. Scale bar equals $20 \mathrm{~mm}$. 


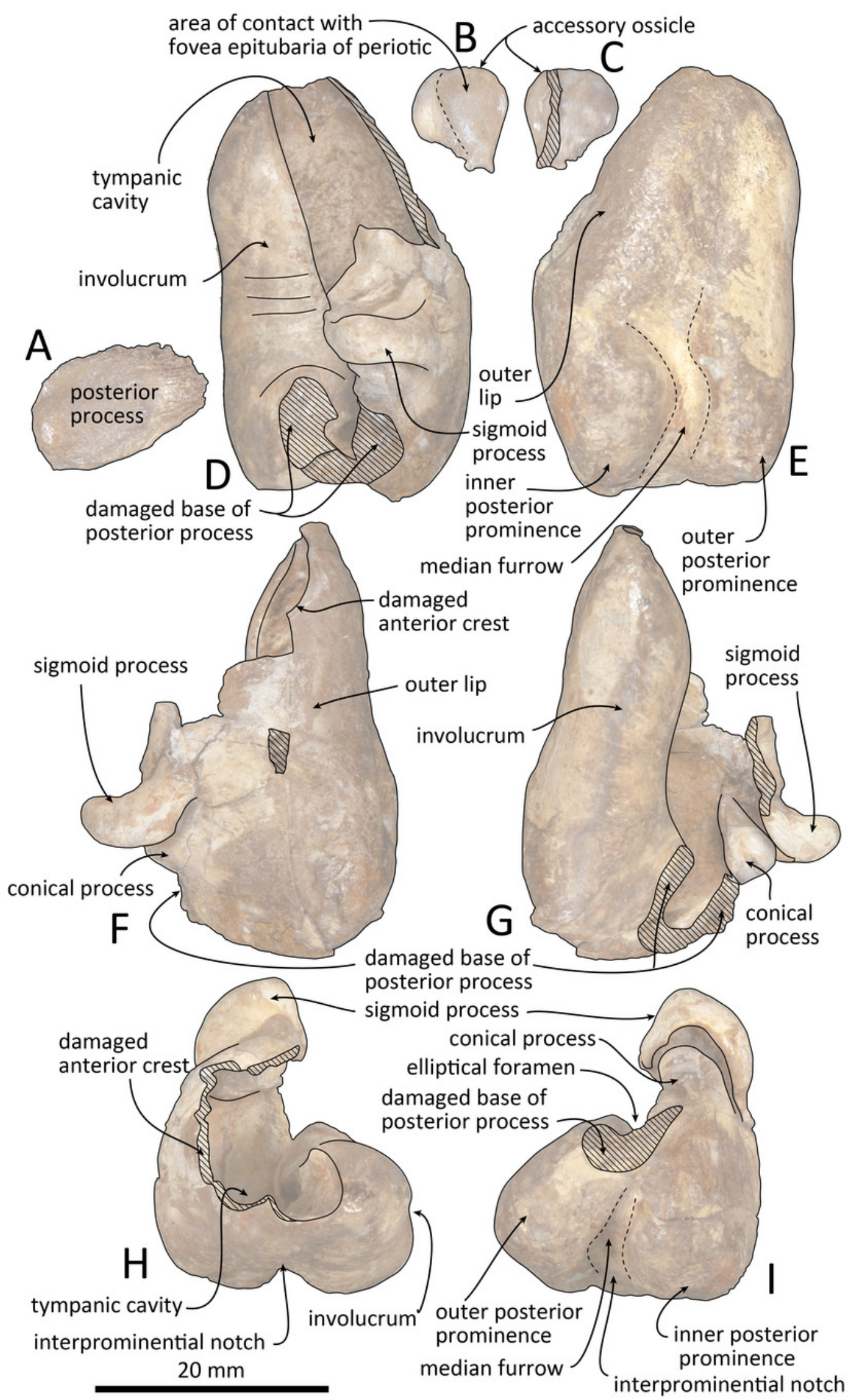




\section{Figure 11}

Malleus, tooth, mandible and vertebra of Kentriodon sugawarai, sp. nov., holotype, NMHF 999, with anatomical interpretations.

(A-F) right malleus. (A) ventral view. (B) dorsal view. (C) medial view. (D) lateral view. (E) anterior view. (F) posterior view. (G-J) probable upper tooth. (G) distal view. (H) mesial view. (I) lingual view. (J) labial view. (K-L) ascending ramus of the left mandible. (K) medial view. (L) lateral view. (M-N) horizontal ramus of the right mandible. (M) lingual view. (N) labial view. (O-P) ventral half of the atlas. (O) anterior view. (P) posterior view. Scale bar equals 20 $\mathrm{mm}$. 

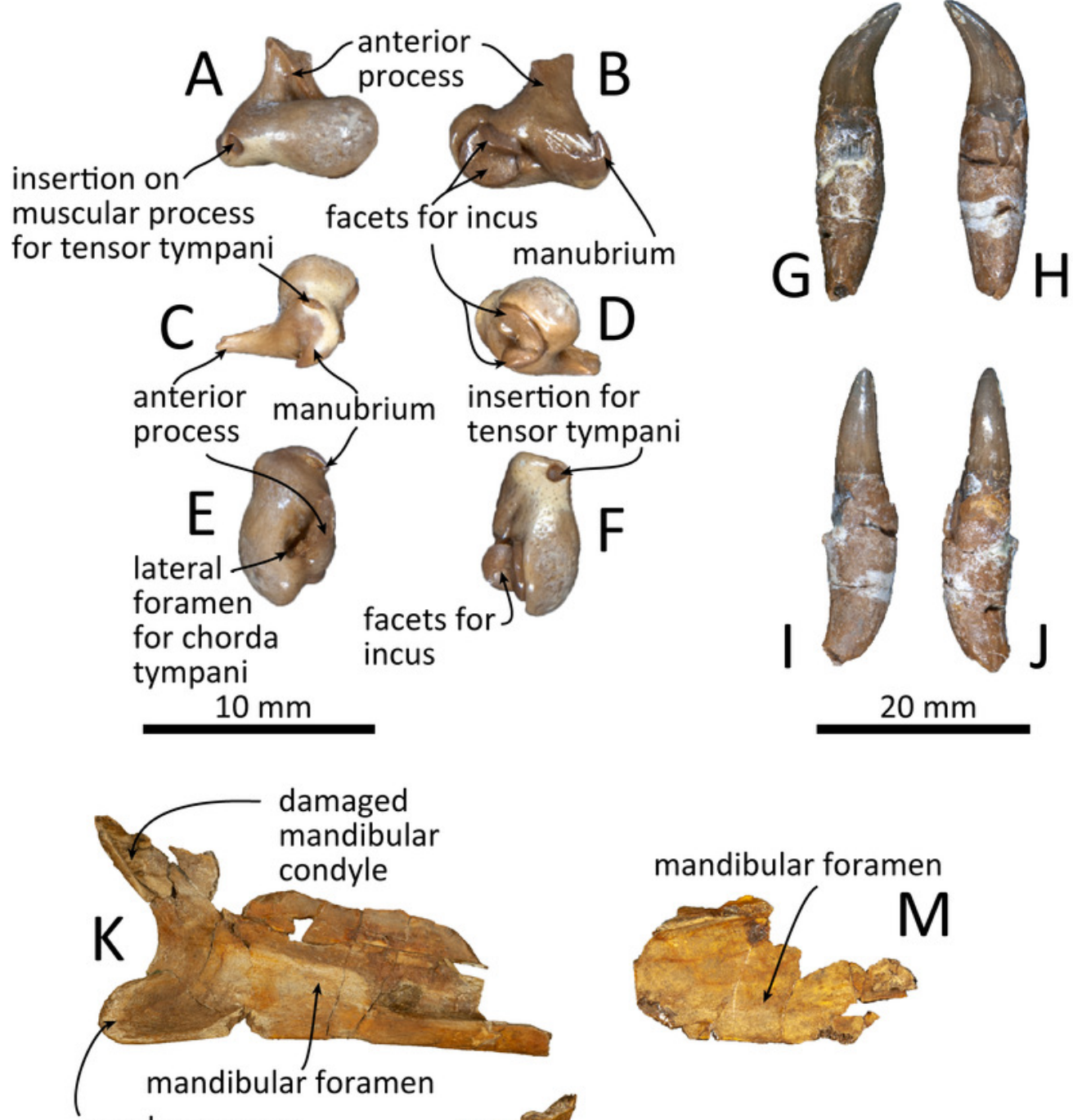

angular process
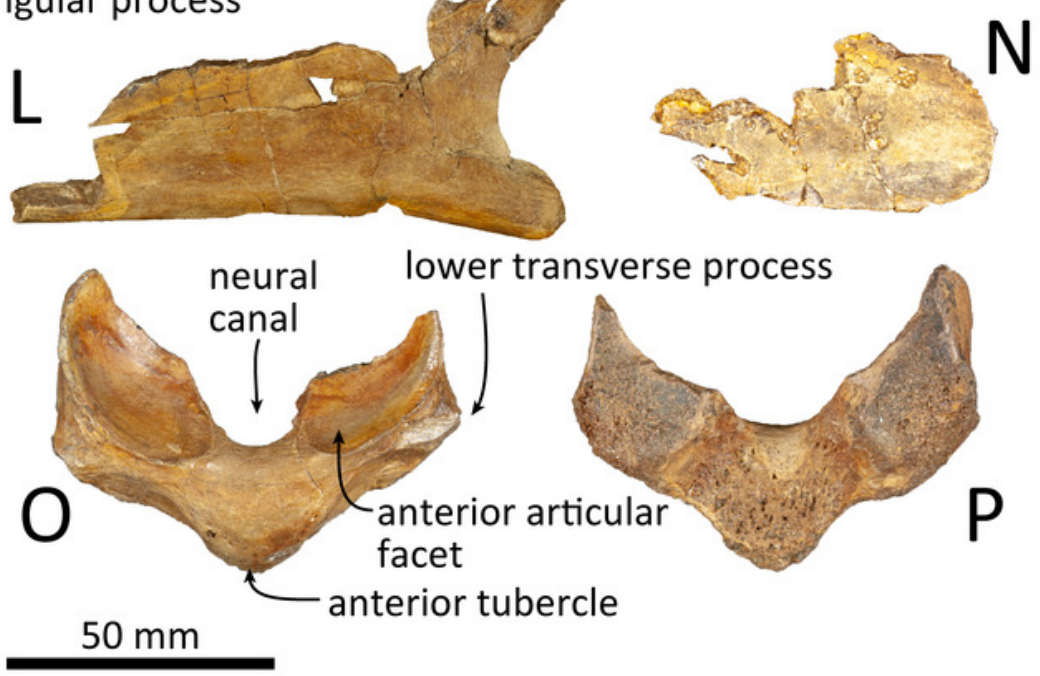


\section{Figure 12}

$50 \%$ majority consensus tree showing the phylogenetic relationships of Kentriodon sugawarai, sp. nov.

50\% majority consensus tree resulting from 256 most parsimonious trees with trees constraint by the molecular consensus trees from McGowen, Spaulding \& Gatesy (2009), McGowen et al. (2011) and McGowen et al. (2020), 3424 steps long, with the consistency index $=0.197$ and the retention index $=0.564$. Numbers below nodes indicate bootstrap values ( 1,000 replicates). The values lower than $50 \%$ were omitted. The interspecific relationships within clades Physeteroidea, Ziphiidae, Delphinidae, Phocoenidae, and Monodontidae were omitted and these groups were collapsed to families/superfamilies. 


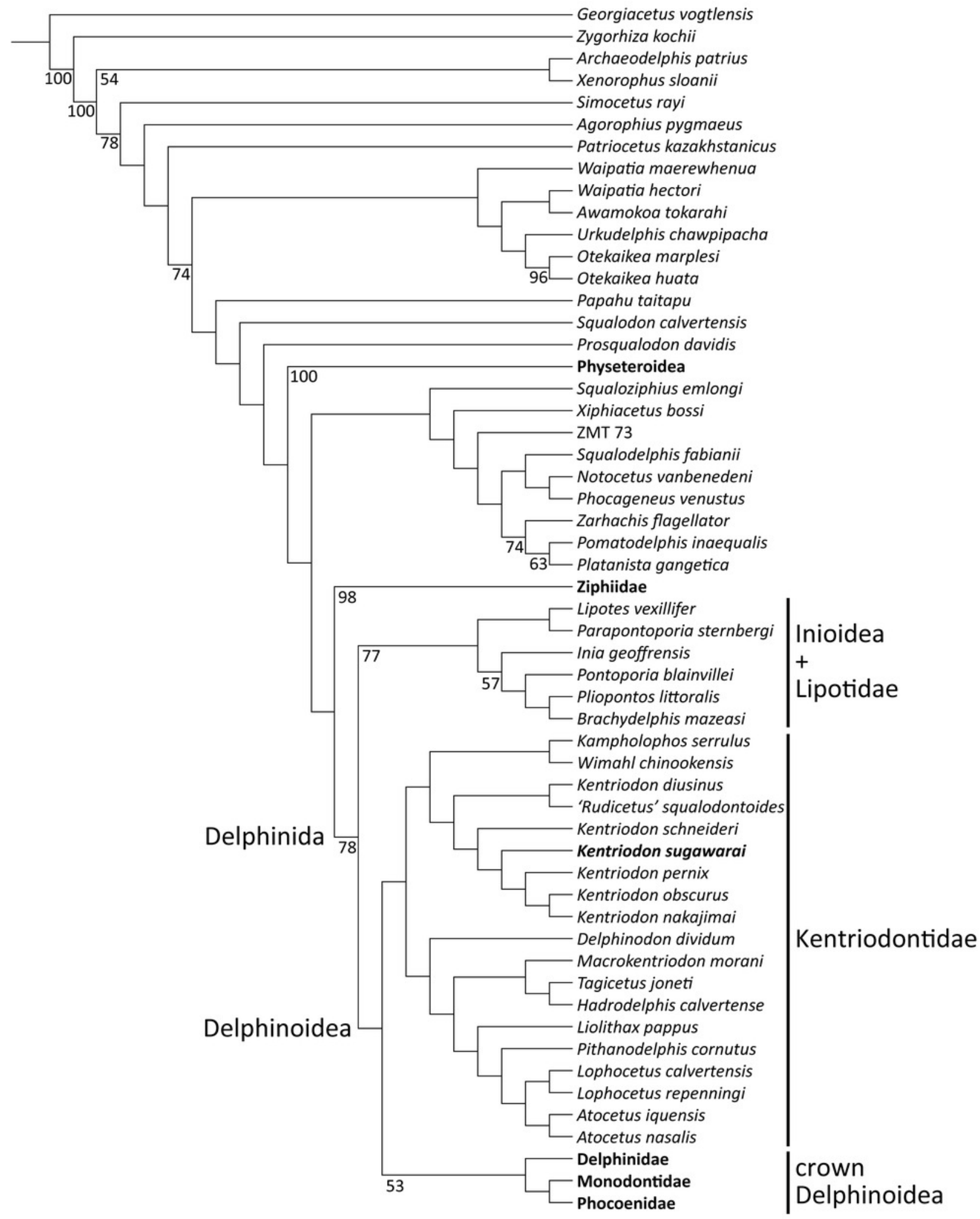




\section{Figure 13}

Strict consensus tree showing the phylogenetic relationships of Kentriodon sugawarai, sp. nov.

Strict consensus tree resulting from 256 most parsimonious trees with trees constraint by the molecular consensus trees from McGowen, Spaulding \& Gatesy (2009), McGowen et al. (2011) and McGowen et al. (2020), 3424 steps long, with the consistency index $=0.197$ and the retention index $=0.564$. The interspecific relationships within clades Physeteroidea, Ziphiidae, Delphinidae, Phocoenidae, and Monodontidae were omitted and these groups were collapsed to families/superfamilies. 


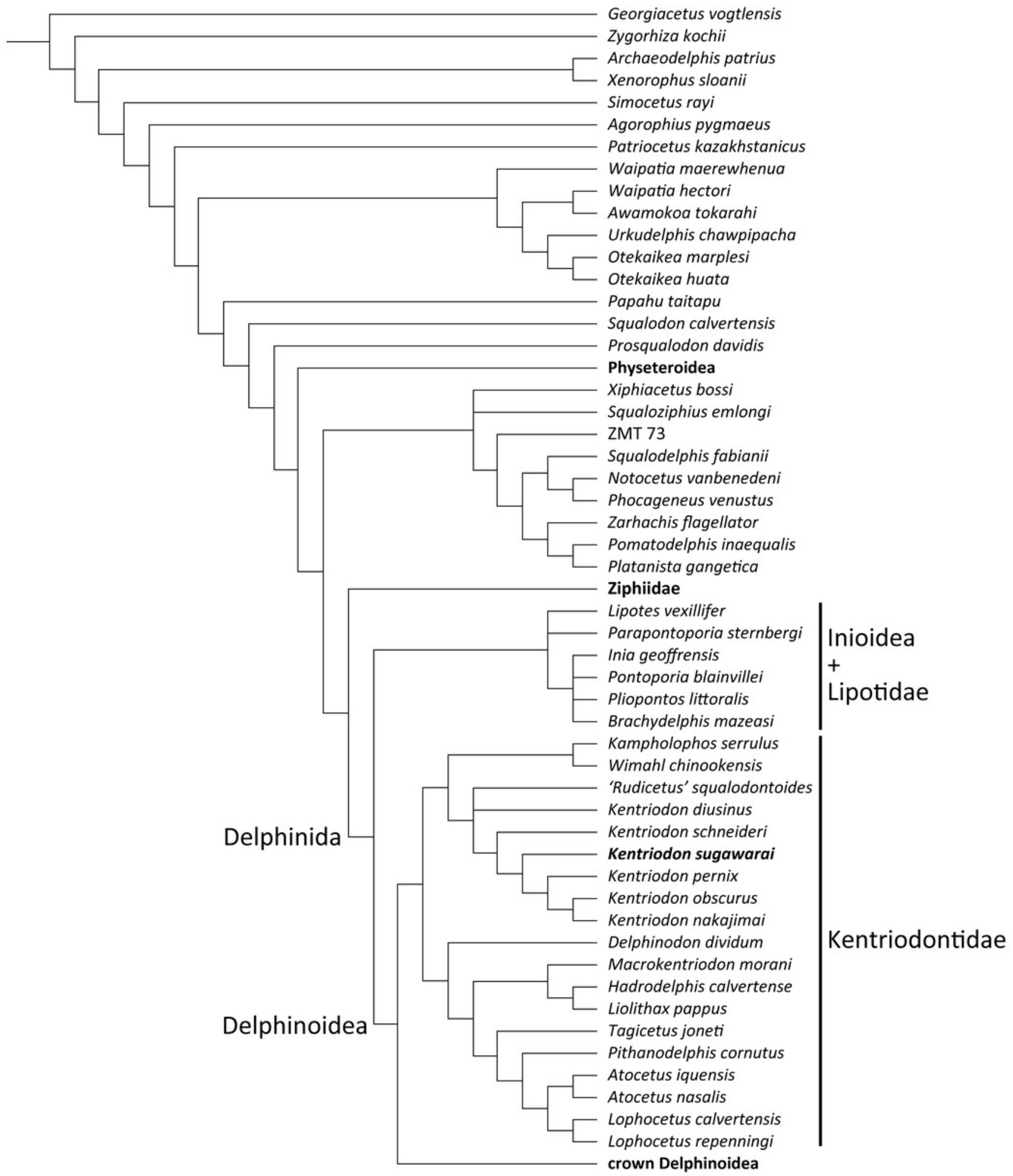




\section{Figure 14}

Several hypotheses of the phylogeny for the Delphinida.

Topologies have been modified from previous studies, all trees are selected from unweighted and unordered. The kentriodontid lineages are colored in red. (A) unconstrained tree from Geisler et al., 2011; Geisler, Godfrey \& Lambert, 2012. (B) unconstrained tree from Murakami et al., 2012; Murakami et al., 2014. (C) molecular constraint tree from Tanaka \& Fordyce, 2014; Tanaka \& Fordyce, 2016; Tanaka et al., 2017. (D) molecular constraint tree from Lambert et al., 2017; Peredo, Uhen \& Nelson, 2018; Kimura \& Hasegawa, 2019. (E) molecular constraint tree from Lambert et al., 2018a. (F) molecular constraint tree from this paper.

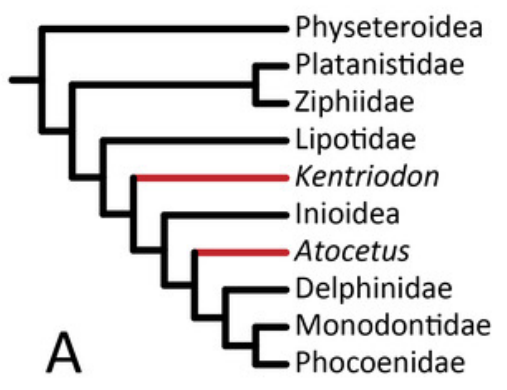

Geisler et al., 2011

Geisler, Godfrey \& Lambert, 2012

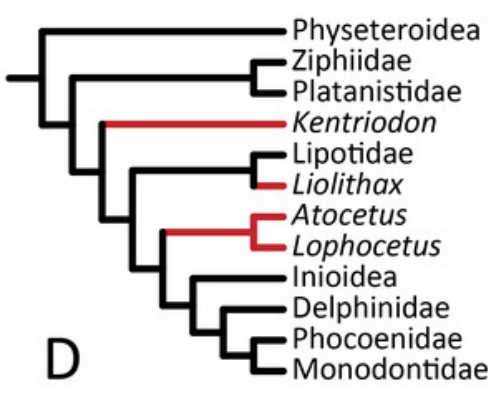

Lambert et al., 2017

Peredo, Uhen \& Nelson, 2018

Kimura \& Hasegawa, 2019

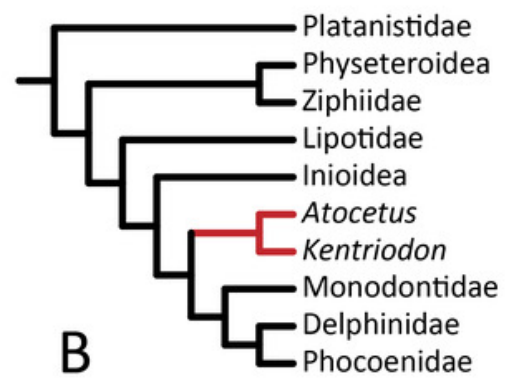

Murakami et al., 2012

Murakami et al., 2014

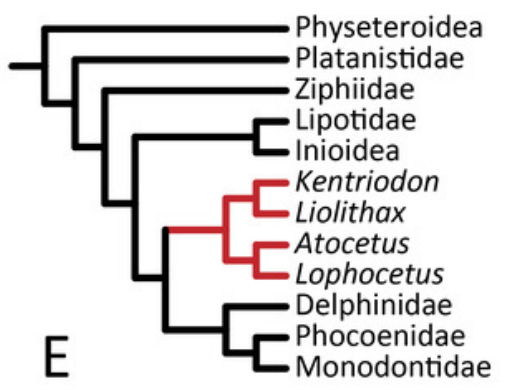

Lambert et al., 2018a

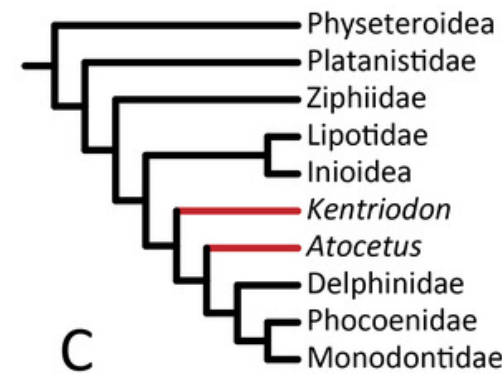

Tanaka \& Fordyce, 2014

Tanaka \& Fordyce, 2016

Tanaka et al., 2017

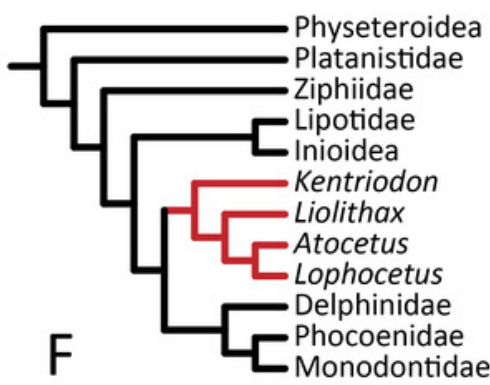

Guo \& Kohno (this paper) 


\section{Table $\mathbf{1}$ (on next page)}

Measurements (in $\mathrm{mm}$ ) for the skull and tympanoperiotic of Kentriodon sugawarai sp. nov., holotype, NMHF 999.

Abbreviations: e, estimate; +, not complete. 


\begin{tabular}{ll}
\hline Dimension & Measurement \\
\hline Skull
\end{tabular}

Condylobasal length, from tip of rostrum to hindmost margin of occipital

$186.2+$

condyles

Length of rostrum, from tip to line across hindmost limits of antorbital notches $15.1+$

Width of rostrum at base, along line across hindmost limits of antorbital $\quad 107.2 \mathrm{e}$

notches

Maximum length of frontal at the vertex

19.3

$\begin{array}{lr}\text { Width of the foramen magnum } & 21.8\end{array}$

Width of premaxillae at posterior extremity $\quad 61.4$

Width of nasal bones $\quad 53.4$

Distance from tip of rostrum to external nares (to mesial end of anterior margin $56.0+$

of right naris)

Distance from tip of rostrum to internal nares (to mesial end of posterior $56.8+$

margin of right pterygoid)

Greatest preorbital width

$181.2 \mathrm{e}$

Greatest postorbital width

$215.0 \mathrm{e}$

Least supraorbital width

$179.2 \mathrm{e}$

Greatest width of external nares

41.8

Greatest width across zygomatic processes of squamosals $\quad 161.0+$

Greatest width of premaxillae $\quad 101.4 \mathrm{e}$

Greatest parietal width

$138.0+$

Greatest length of left temporal fossa, measured to external margin of temporal

crest

Greatest width of left temporal fossa perpendicular to greatest length

54.5

Major diameter of left temporal fossa proper

41.6

Minor diameter of left temporal fossa proper

$48.1+$

Distance from foremost end of junction between nasals to hindmost point of

34.6

margin of nuchal crest

Length of left orbit-from apex of preorbital process of frontal to apex of

52.4

postorbital process

Length of antorbital process of left lacrimal

Greatest width of internal nares

$71.4 \mathrm{e}$

Greatest length of left pterygoid

47.6

Width across occipital condyles

70.5

Periotic

Total length

Length of anterior process

17.8

Width at pars cochlearis

13.2

Length of posterior bullar facet

10.5

Width of posterior bullar facet

Length of pars cochlearis, from anterior to posterior margin

Tympanic Bulla

Total length without posterior process as preserved

37.4

Total width as preserved

21.8

Width of inner posterior prominence 
Atlas

Width of atlas

69.1

Length of atlas

$62.9+$

Greatest width of facet for occipital condyle

24.9

1

Peer) reviewing PDF | (2020:08:52427:2:0:CHECK 17 Jan 2021) 